\title{
Global identification and analysis revealed differentially expressed IncRNAs associated with meiosis and low fertility in autotetraploid rice
}

Xiang $\mathrm{Li}^{1,2,3+}$, Muhammad Qasim Shahid ${ }^{1,2,3+}$ (D) Minsi Wen ${ }^{3}$, Shuling Chen ${ }^{3}$, Hang Yu ${ }^{1,2,3}$, Yamin Jiao ${ }^{1,2,3}$, Zijun Lu ${ }^{1,2,3}$, Yajing $\mathrm{Li}^{1,3}$ and Xiangdong Liu ${ }^{1,2,4,3^{*}}$ (D)

\begin{abstract}
Background: Autotetraploid rice is a useful germplasm for polyploid rice breeding. Our previous research showed that non-coding RNAs might be associated with low fertility in autotetraploid rice. However, little information is available on long non-coding RNAs (IncRNAs) involved in the low fertility of autotetraploid rice. In the present study, RNA-seq was employed to detect the differentially expressed meiosis-related IncRNAs in autotetraploid rice, and gene overexpression and knock out experiments were used to validate the potential function of candidate InCRNA.

Results: A total of 444 differentially expressed IncRNAs (DEL) were detected during anther and ovary meiosis in autotetraploid rice. Of these, 328 DEL were associated with the transposable elements, which displayed low expression levels during meiosis in autotetraploid rice. We used rapid amplification of CDNA ends (RACE) assay to validate $10 \mathrm{DEL}$ and found that the IncRNAs were not assembly artifacts, and six of them were conserved in tetraploid rice. Moreover, 237 and 20 IncRNAs were associated with pollen mother cell (PMC) and embryo sac mother cell (EMC) meiosis in autotetraploid rice, respectively. The differential expressions of some meiosis-related targets and its DEL regulator, including MEL1 regulated by TCONS_00068868, LOC_Os12g41350 (meiotic asynaptic mutant 1) by TCONS_00057811 in PMC, and LOC_Os12g39420 by TCONS_00144592 in EMC, were confirmed by qRT-PCR. TCONS_00057811, TCONS_00055980 and TCONS_00130461 showed anther specific expression patterns and were found to be highly expressed during meiosis. CRISPR/Cas9 editing of IncRNA57811 displayed similar morphology compared to wild type. The overexpression of IncRNA57811 resulted in low pollen fertility (29.70\%) and seed setting (33\%) in rice.
\end{abstract}

Conclusion: The differential expression levels of IncRNAs, associated with transposable elements and meiosisregulated targets, might be endogenous noncoding regulators of pollen/embryo sac development that cause low fertility in autotetraploid rice. The results enhance our understanding about rice IncRNAs, and facilitate functional research in autotetraploid rice.

Keywords: Autotetraploid rice, Embryo sac mother cell, IncRNAs (long non-coding RNAs), Male sterility, Meiosis, Pollen mother cell

\footnotetext{
* Correspondence: xdliu@scau.edu.cn

${ }^{\dagger}$ Xiang Li and Muhammad Qasim Shahid contributed equally to this work.

${ }^{1}$ State Key Laboratory for Conservation and Utilization of Subtropical

Agro-Bioresources, South China Agricultural University, Guangzhou 510642,

China

${ }^{2}$ Guangdong Provincial Key Laboratory of Plant Molecular Breeding, South

China Agricultural University, Guangzhou 510642, China

Full list of author information is available at the end of the article
}

(c) The Author(s). 2020 Open Access This article is distributed under the terms of the Creative Commons Attribution 4.0 International License (http://creativecommons.org/licenses/by/4.0/), which permits unrestricted use, distribution, and

reproduction in any medium, provided you give appropriate credit to the original author(s) and the source, provide a link to the Creative Commons license, and indicate if changes were made. The Creative Commons Public Domain Dedication waiver (http://creativecommons.org/publicdomain/zero/1.0/) applies to the data made available in this article, unless otherwise stated. 


\section{Background}

Whole genome doubling (WGD), or polyploidy, has been known as a vital evolutionary force for genetic diversity in plants. About 35\% 70\% angiosperms have undergone at least one round of genome duplication, such as wheat, cotton and brassica [1]. A variety of genome alterations caused by polyploidy, including creating new source of redundant genes, genome rearrangements and genome-wide subfunctionalization and neofunctionalization $[2,3]$. The potential advantages of plant genome reconstruction can be utilized with the newly developed resources of genomics for crop improvement [4].

Autotetraploid rice, as a useful germplasm, has more biological advantages than the diploid rice that may become a new way for rice breeding [5-7]. However, low fertility, an unfavorable trait, is one of the major barriers in commercial production of polyploid rice [8-11]. Meiosis is an essential biological process in the life cycle of sexual reproduction in plants [12]. Normal chromosomes segregation in meiosis is one of the most important challenges to polyploids [13, 14]. Multivalents during meiosis often generated massively in the newly formed polyploids [15-18]. Cytogenetic analysis revealed that chromosomal abnormalities, abnormal development processes of pollens and embryo sacs were the main reasons for low fertility in autotetraploid rice $[16,19,20]$. Transcriptome analysis revealed that polyploidy enhances the $F_{1}$ pollen sterility multi-loci interactions which lead to meiosis abnormalities and pollen sterility in autotetraploid rice hybrids [19]. In addition, some meiosis-related microRNAs were identified that may interrupt the chromosome behavior in pollen mother cells (PMC) of autotetraploid rice [21]. Recently, differential expression patterns of small RNAs during embryo sac development in autotetraploid rice have been reported to associate with sterility, especially during megasporocyte [20].

Non-coding RNAs (ncRNAs) cannot encode proteins; however, they play a key role in regulation of transcriptional, posttranscriptional and epigenetic mechanisms. Long non-coding RNAs (lncRNAs) are one of the important types of ncRNAs, with a length of more than $200 \mathrm{nt}$, and usually exhibited tissue/developmental-stagespecific expression patterns [22]. LncRNAs have been identified in many plants, including rice, maize, sunflower and strawberry [23-25], and some of them were reported to associate with reproductive processes in rice [26]. Additionally, the lncRNAs of rice anthers before flowering, pistils before flowering, spikelets 5 days after pollination and shoots 14 days after germination have been characterized, and several important lncRNAs were exclusively identified in young panicles, which showed a profound impact on rice fertility [27]. Recently, overexpression of LAIR increased grain yield and up-regulated the expression of several leucine-rich repeat receptor kinase genes in rice [28]. Meanwhile, lncRNAs played a pivotal role to small RNAs population, which could act as small RNAs precursors, miRNAs targets and decoys [29].

Although information on small RNAs and transcriptome sequencing in autotetraploid rice are available [11, 20], the expression patterns of lncRNAs associated with meiosis in autotetraploid rice are still poorly understood. The present study was planned to investigate the expression levels of lncRNAs in anther and ovary during meiosis in an autotetraploid rice, Taichung $65-4 x$, and its diploid counterpart (Taichung 65) by high-throughput sequencing. We sought to distinguish the lncRNAs changes between autotetraploid and diploid rice, and to determine the relationships between gene expression profiles and spikelet sterility.

\section{Results}

\section{Identification and characterization of IncRNAs in rice} anther and ovary

Previous study showed that the pollen fertility of Taichung $65-4 x$ was lower than the diploid counterpart [11]. Here, embryo sac fertility of Taichung $65-4 \mathrm{x}$ was observed by Whole-mount eosin B-staining confocal laser scanning microscopy (Fig. 1), which was $62.15 \%$. Therefore, anthers and corresponding ovaries of Taichung 65 and Taichung 65-4x from pre-meiotic interphase to meiosis prophase I (early meiosis stage) were collected for transcriptome sequencing. After a genome-wide systematic filtration, a total of 4859 confident lncRNAs (FPKM $>0.5$ in at least one library) were obtained, including 4018 intergenic lncRNAs, 790 antisense lncRNAs, and 51 sense lncRNAs, and used for further analysis (Additional file 1: Fig. S1A; Additional file 2: Table S1). Venn analysis revealed that most of the lncRNAs were specifically expressed in anthers/ovaries, and a total of 1282 and 2025 lncRNAs were specifically detected in the rice reproductive tissues of Taichung 65 and Taichung 65-4x, respectively (Additional file 1: Fig. S1B). Moreover, 28\% lncRNAs were exclusively expressed in the anthers of Taichung 65-4x.

We further characterized the features of lncRNAs, and found that the expression levels of lncRNAs were lower than the protein-coding genes (Additional file 1: Fig. S2A). High proportions of lncRNAs were found with one exon, which differed from the protein-coding genes (Additional file 1: Fig. S2B). The transcript length distribution was not similar between lncRNAs and protein-coding genes. Most of protein-coding genes were longer than $1 \mathrm{~kb}$, whereas majority of lncRNAs were less than $1 \mathrm{~kb}$. The lengths of the lncRNAs, with a mean value of 938 nucleotides, was shorter than the protein-coding genes $($ mean $=1862 \mathrm{bp}$ ) (Additional file 1: Fig. S2C). In addition, shorter ORFs (open reading frames) were observed in lncRNAs (mean = $66.36 \mathrm{aa})$ than protein-coding genes $($ mean $=384.27 \mathrm{aa})$ in 


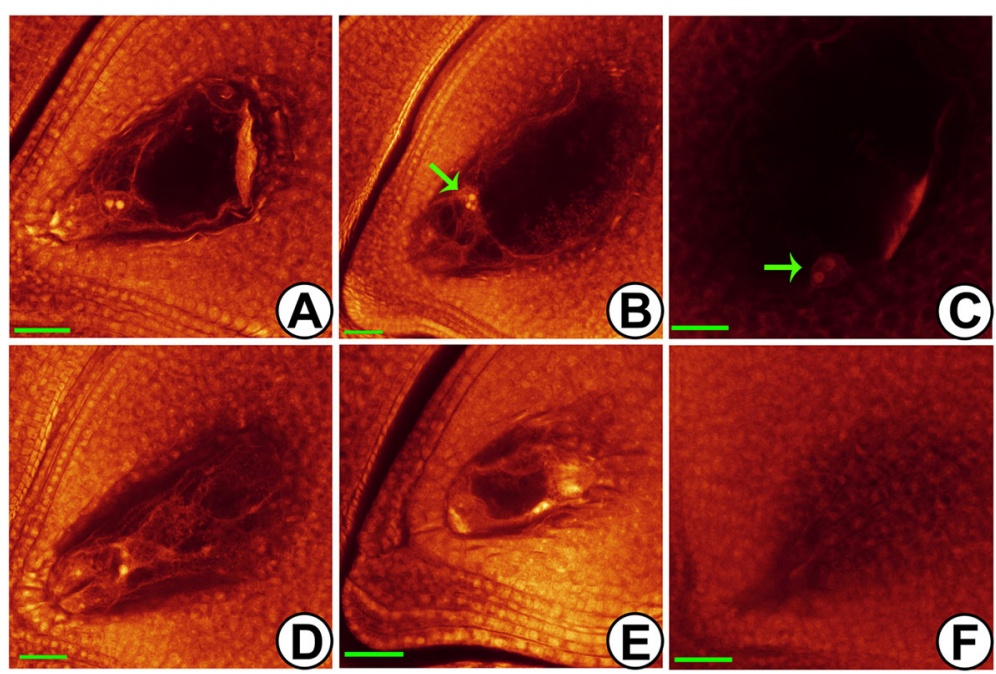

Fig. 1 Cytological observation of embryo sac in Taichung 65-4x by WE-CLSM. a normal embryo sac. b, c abnormal position and number of polar nuclei (green arrow). $\mathbf{d}$ abnormal antipodal cells. e small embryo sac. $\mathbf{f}$ embryo sac degeneration. Bars $=40 \mu \mathrm{m}$

the rice reproductive tissues (Additional file 1: Fig. S2D). Moreover, only a small portion $(4.4 \%)$ of rice reproductive lncRNAs was found to be conserved, including 12 in Arabidopsis, 80 in Brachypodium, 103 in Zea mays, and 161 in Sorghum bicolor. Intriguingly, 11 of 12 conserved lncRNAs in Arabidopsis were also found to be conserved in Brachypodium, Zea mays and Sorghum bicolor (Additional file 2: Table S2).

The full-length of ten IncRNAs were obtained by rapid amplification of cDNA ends (RACE) assay (Fig. 2), including TCONS_00057811, TCONS_00130461, TCONS_00068868, TCONS_00091337, TCONS_00055980, TCONS_00130471, TCONS_00111916, TCONS_00045430, TCONS_00013598 and TCONS_00121908. These lncRNAs could be amplified and existed in the rice which indicated that lncRNAs were not assembly artifacts; however, no DNA variations were found between Taichung 65 and Taichung 65-4x. TCONS 00057811 was located in intergenic region (25685721-25, $686,497,-$ strand) on chromosome 12 . The real length of TCONS_00057811 was 777 bp, and it had two exons, which was different from the gene body structure predicted by transcriptome analysis. The length of TCONS_00130461 was $2073 \mathrm{bp}$, which was also different from the transcriptome result. Not only TCONS_00057811 and TCONS_ 00130461, the length of the other eight lncRNAs were different from the predicted fragments (Additional file 1: Fig. S3). Furthermore, phylogenetic tree (MEGA-X) results showed that six lncRNAs were conserved among our rice dataset (re-sequencing data of more than 100 rice lines, including neo-tetraploid, autotetraploid, typical japonica/indica and wild rice lines, and unpublished data), including TCONS_ 00057811, TCONS_00091337, TCONS_00130461, TCONS_00130471, TCONS_00045430 and TCONS_ 00055980 (Additional file 1: Fig. S4).

\section{Differentially expressed IncRNAs in anther and ovary} during meiosis

To characterize the differential expression patterns of lncRNAs, we first figured out the lncRNAs associated with anther and ovary. By cluster analysis, 78 antherpreferred and 222 ovary-preferred lncRNAs, which highly/specifically expressed in anther/ovary, were identified in Taichung 65 (defined as anther- and ovarypreferred-2x), and 222 anther-preferred and 394 ovarypreferred lncRNAs were detected in Taichung 65-4x (defined as anther- and ovary-preferred-4x), respectively (Additional file 1: Fig. S5; Additional file 2: Table S1). Of the preferred lncRNAs in ovary, 133 lncRNAs were detected in both Taichung 65 and Taichung 65-4x during meiosis (co-ovary-preferred), and 34 lncRNAs were shared by the Taichung 65 and Taichung $65-4 \mathrm{x}$ in anther during meiosis (co-anther-preferred).

A total of 431 differentially expressed lncRNAs (DEL) were detected in anthers of Taichung 65-4x compared to the Taichung 65 (DEL-anther), of these 221 and 210 lncRNAs showed up- and down-regulation, respectively (Additional file 2: Table S3). Besides, a small portion of DEL (32 in total) was also found in ovaries of Taichung 65-4x compared to Taichung 65 (DEL-ovary), and 8 and 24 lncRNAs exhibited up- and down-regulation, respectively. 19 common DEL were detected between DELanther and DEL-ovary by venn analysis, and 17 out of these showed similar differential expression patterns with 3 co-up-regulated and 14 co-down-regulated DEL in autotetraploid rice (Additional file 1: Fig. S6). Furthermore, we compared the 431 DEL-anther and 32 DELovary with the anther-preferred lncRNAs and ovarypreferred lncRNAs by venn analysis, respectively. 27 out of 34 co-anther-preferred lncRNAs showed differential 


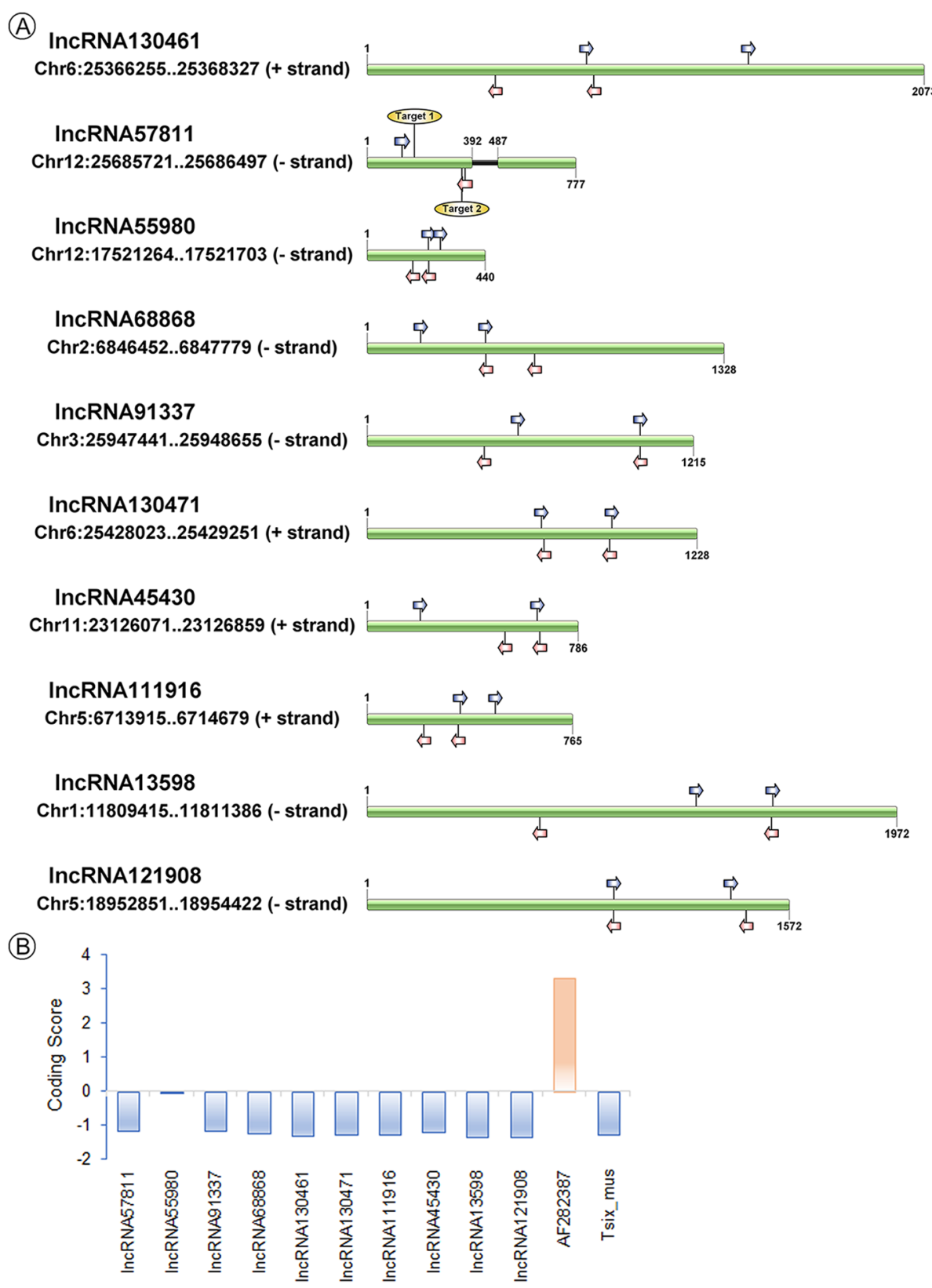

Fig. 2 Features of the ten IncRNAs validation by RACE assay. a Structures of the IncRNAs. Blue and red arrows indicated the 3' Race outer/inner primers and 5' Race outer/inner primers, respectively. Target 1 and Target 2 represent the position of CRISPR/Cas 9 target sequence. The fulllength of IncRNAs was drawn by IBS software (http://ibs.biocuckoo.org/). b Analysis of the coding potential of the ten IncRNAs. Transcripts with scores $<-1$ and $>1$ are marked as non-coding or coding in CPC analysis [30]. AF282387 and Tsix_mus are provided as coding examples and noncoding examples by CPC analysis

expression patterns in Taichung 65-4x (DEL-anther: type 1). Surprisingly, these 27 DEL showed down-regulation in Taichung 65-4x compared to Taichung 65 (Additional file 1: Fig. S7A). In addition, 25 (DEL-anther: type 2) and 40 DEL (DEL-anther: type 3) were overlapped with the anther-preferred-2x and anther-preferred-4x lncRNAs, respectively. Similarly, 16 DEL were found to be associated with co-ovary-preferred lncRNAs (DEL-ovary: type
1). Interestingly, 15 out of $16 \mathrm{DEL}$ were found to be down-regulated in Taichung 65-4x compared to Taichung 65, except TCONS_00019924 (Additional file 1: Fig. S7B). Six (DEL-ovary: type 2) and three DEL (DELovary: type 3) were found to be overlapped with the ovary-preferred-2x and ovary-preferred-4x lncRNAs, respectively. The rest of the DEL in anther/ovary was defined as type 4. 
In addition, we used BLAST search to compare the sequences and 160 lncRNAs displayed more than 90\% sequence similarity with Zhang et al. [27]. Of these, 56 showed differential expression patterns between Taichung 65-4x and Taichung 65 (Additional file 2: Table S4). Among the 56 DEL, 18 showed differential expressions in Taichung 65-4x anthers, which highly expressed in anthers [27], such as TCONS_00130461. Two DEL were found to be differentially expressed in Taichung $65-4 \mathrm{x}$ ovaries that showed pistils expression patterns in Zhang's results, such as TCONS_00054234.

\section{Small RNA populations and their relationships with differentially expressed IncRNAs in autotetraploid rice during meiosis}

By small RNAs sequencing, 1034 miRNAs (i.e. 357 known miRNAs and 677 novel miRNAs) and 17,609 phasiRNAs (i.e. 15,992 were $21 \mathrm{nt}$ in length and 1617 were $24 \mathrm{nt}$ ) were detected in the rice reproductive tissues (Additional file 2: Table S5 and S6). According to the model described by Boerner and McGinnis [29], these types of small RNAs were aligned to the 4859 confident lncRNAs to detect the small RNAs precursor in lncRNAs.

By aligning miRNA precursors to lncRNAs, 27 lncRNAs were predicted to be the precursors of 43 miRNAs (Additional file 2: Table S7). Nine of these showed differential expression patterns in autotetraploid rice anther, and one DEL-anther (Type 1) was corresponding to the differentially expressed miRNA (DEM) (i.e. TCONS_00160902 was predicted as a precursor of $z m a-m i R 2275 b-5 p \_1 s s 12 C G$ ). A total of 98 lncRNAs were predicted to be the precursors of 949 phasiRNAs, including 63 lncRNAs as precursors to 433 21 nt-phasiRNAs $(2.70 \%)$ and 35 lncRNAs as precursors to 51624 nt-phasiRNAs (31.91\%). Of these 98 lncRNAs, 29 showed differential expression patterns (down-regulation) in autotetraploid rice anther compared to diploid, but no one found to be differentially expressed in ovary of autotetraploid rice (Additional file 2: Table S8). Moreover, DELanther (Type 1) could generate most of phasiRNAs (270 phasiRNAs/13 DEL-anther) (Table 1). Interestingly, majority of the DEL (22 of $29 \mathrm{DEL}$ ) were found to be the precursors of 24 nt-phasiRNAs. In addition, nine down-regulated
DEL were associated with 11 down-regulated phasiRNAs in Taichung 65-4x. Taken together, 39 DEL were associated with small RNAs, which could serve as precursors and showed down-regulation in autotetraploid rice (Additional file 2: Table S3).

Surprisingly, we could not identify any DEL-anther/ ovary that predicted to be the target of a DEM in autotetraploid rice during meiosis by psRNATarget [31] (Additional file 2: Table S9). Moreover, there was no DEL-anther or DEL-ovary that could be the target mimic of the DEM in Taichung 65-4x, which decoy miRNAs and blocked the interaction between miRNAs and their authentic targets.

\section{Repetitive elements were associated with differentially expressed IncRNAs in autotetraploid rice during meiosis} A series of transposable elements (TEs) genes in anther and ovary were observed, and the relative expression levels of TEs were more abundant in the anthers of Taichung 65 than Taichung 65-4x, especially DNA transposons (i.e. Class II TEs, such as the Helitron family) (Fig. 3A). However, no remarkable changes in TEs were observed in ovary between diploid and autotetraploid rice. Majority of the IncRNAs (73.22\%) were overlapped with repeat sequences. Of these TEs-associated lncRNAs, 66.36\% carried Class II and 19.08\% carried retrotransposons (Class I), while the remaining $14.56 \%$ contained both of them. Helitron family was the most frequent sub-class in Class II, whereas the Gypsy family constituted a major portion of Class I (Additional file 1: Fig. S8). The relative expression levels of TEs-lncRNAs also showed similar distribution of TEs genes between Taichung 65-4x and Taichung 65 (Fig. 3B). The differential expression patterns of some TEs and TEs-lncRNAs in anther were confirmed by qRT-PCR (Additional file 1: Fig. S9).

The TEs-associated IncRNAs showed differential expressions in autotetraploid rice anther and ovary, with a percentage of $73.78 \%(318 / 431)$ and $81.25 \%(26 / 32)$ in DEL, respectively (Additional file 2: Table S10). Of the TEs-associated DEL (TEs-DEL), down-regulated TEsDEL-anther and TEs-DEL-ovary were mostly found to be associated with TEs (Table 2). Down-regulated TEs-

Table 1 The number of small RNAs generated by differentially expressed IncRNAs in autotetraploid rice

\begin{tabular}{|c|c|c|c|c|c|c|c|c|c|}
\hline \multirow[t]{2}{*}{ Tissue } & \multirow{2}{*}{$\begin{array}{l}\text { Small } \\
\text { RNAs }\end{array}$} & \multicolumn{2}{|l|}{ Type 1} & \multicolumn{2}{|l|}{ Type 2} & \multicolumn{2}{|l|}{ Type 3} & \multicolumn{2}{|l|}{ Type 4} \\
\hline & & No. DEL & No. small RNAs & No. DEL & No. small RNAs & No. DEL & No. small RNAs & No. DEL & No. small RNAs \\
\hline \multirow[t]{2}{*}{ Anther } & miRNAs & 2 & 5 & 0 & 0 & 0 & 0 & 7 & 22 \\
\hline & phasiRNAs & 13 & 270 & 10 & 152 & 1 & 20 & 5 & 25 \\
\hline \multirow[t]{2}{*}{ Ovary } & miRNAs & 2 & 8 & 0 & 0 & 0 & 0 & 0 & 0 \\
\hline & phasiRNAs & 0 & 0 & 0 & 0 & 0 & 0 & 0 & 0 \\
\hline
\end{tabular}

Type 1: The DEL overlapped with the co-anther-preferred/co-ovary-preferred IncRNAs of Taichung 65-4x and Taichung 65

Type 2: The DEL overlapped with anther-preferred/ovary-preferred IncRNAs of Taichung 65

Type 3: The DEL overlapped with anther-preferred/ovary-preferred IncRNAs of Taichung 65-4x

Type 4: The rest of the DEL in anther/ovary 


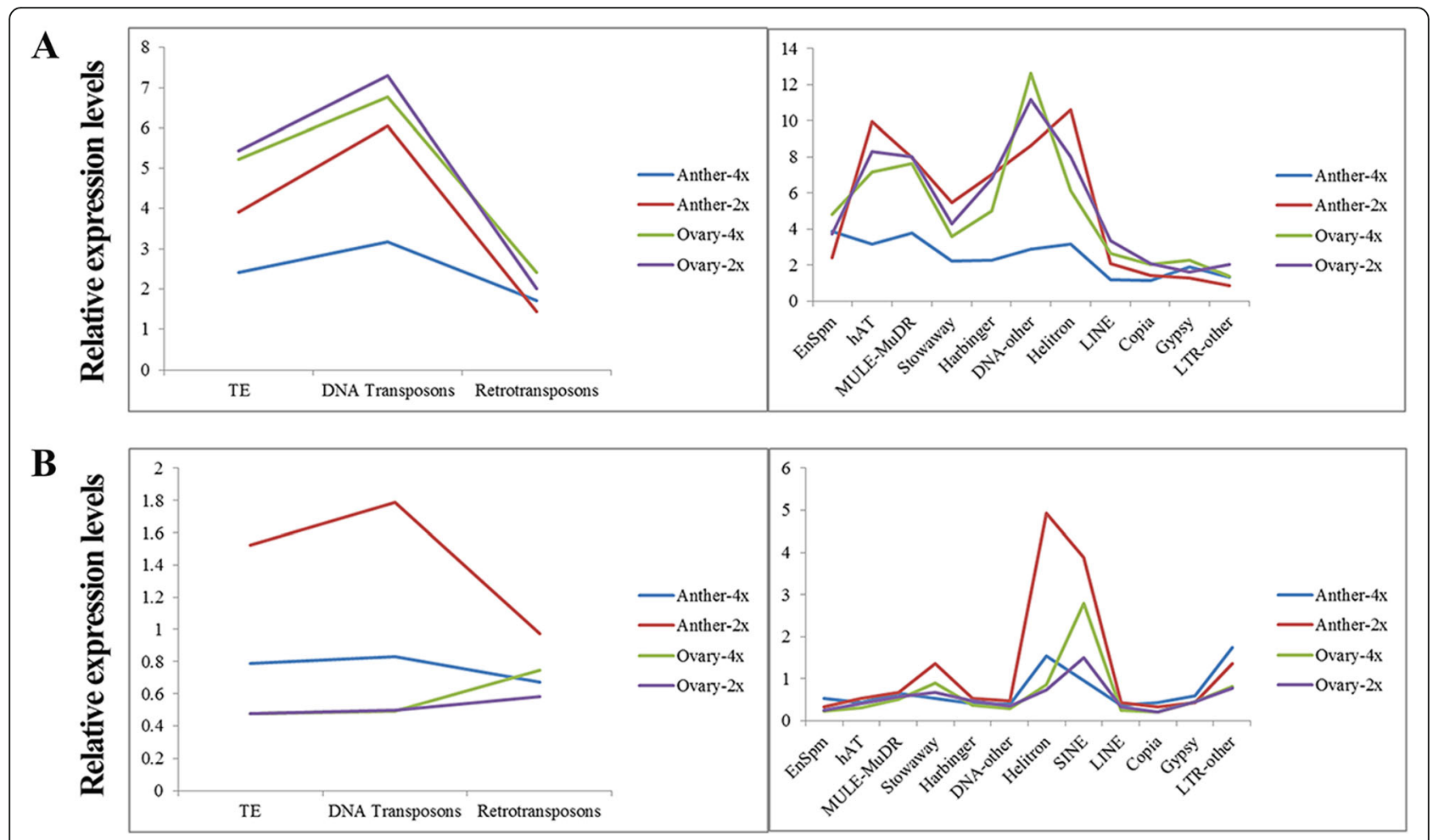

Fig. 3 The relative expression levels of transposable elements (TE)-associated genes (a) and IncRNAs (b) in autotetraploid and diploid rice

DEL-anther were abundantly found in Class II, except EnSpm family, whereas up-regulated TEs-DEL-anther have a great relationship with Gypsy families of Class I in Taichung 65-4x anther. In addition, Helitron and Stowaway families were more related to TEs-DEL-anther (Type 1) compared to other types, and Helitron family was also detected in TEs-DEL-ovary (Type 1) (Additional file 3: Table S11).

Table 2 Distribution of the transposable elements (TEs)-related differentially expressed IncRNAs (DEL) in autotetraploid rice

\begin{tabular}{|c|c|c|c|c|c|}
\hline \multirow{2}{*}{$\begin{array}{l}\text { Transposable } \\
\text { elements }\end{array}$} & \multirow[t]{2}{*}{ Family } & \multicolumn{2}{|l|}{ Anther } & \multicolumn{2}{|l|}{ Ovary } \\
\hline & & Down & up & Down & up \\
\hline \multirow[t]{7}{*}{ DNA Transposons } & Helitron & 50 & 4 & 8 & 1 \\
\hline & Harbinger & 49 & 6 & 3 & 0 \\
\hline & Stowaway & 47 & 1 & 8 & 4 \\
\hline & MULE-MUDR & 38 & 11 & 2 & 1 \\
\hline & hAT & 30 & 1 & 6 & 1 \\
\hline & DNA-other & 26 & 1 & 2 & 0 \\
\hline & EnSpm & 26 & 70 & 4 & 0 \\
\hline \multirow[t]{5}{*}{ Retrotransposons } & SINE & 8 & 3 & 1 & 1 \\
\hline & LINE & 12 & 0 & 1 & 0 \\
\hline & LTR-other & 5 & 0 & 0 & 0 \\
\hline & Copia & 6 & 10 & 0 & 0 \\
\hline & Gypsy & 20 & 75 & 4 & 3 \\
\hline
\end{tabular}

Target prediction of differentially expressed IncRNAs and classification of pollen mother cell (PMC) and embryo sac mother cell (EMC) meiosis-related targets

To identify the potential targets of lncRNAs could help us to uncover the functions of IncRNAs. In total, 942 potential cis-regulated target genes and 3769 potential trans-regulated target genes were detected, and their target genes also showed differential expression patterns (hereafter referred as DEG) (Additional file 3: Table S12 and S13). Among the potential targets of the DELanther, 25 Gene Ontology (GO) terms were significantly categorized, including flower development, DNA binding and nucleus (Additional file 3: Table S14). Beside, only eight GO terms were significantly enriched among the DEL-ovary, such as response to abiotic stimulus.

Furthermore, we evaluated relationship between the targets predicted by DEM and DEL. A total of 104 and 108 predicted targets were identified from the DEM of anther (DEM-anther) and ovary (DEM-ovary) in Taichung 65-4x compared to the diploid rice, respectively (Additional file 3: Table S15). 76 and 81 targets were specifically predicted by DEM-anther and DEM-ovary, whereas 3739 and 328 targets were specifically predicted by DEL-anther and DEL-ovary, respectively (Additional file 1: Fig. S10). GO analysis showed that plastid was specifically enriched in the targets of DEM-anther, while anatomical structure morphogenesis, regulation of cell 
size and cell differentiation were specifically detected in the targets of DEM-ovary. Moreover, nucleus, response to endogenous stimulus and nucleic acid binding were specifically found in the targets of DEL-anther, and response to abiotic stimulus, secondary metabolic process, and response to extracellular stimulus were specifically identified in the targets of DEL-ovary (Additional file 3: Table S16).

Moreover, we compared the targets with the previous studies to identify the most important meiosis-related targets [32-35]. By using the predicted targets of DELanther, 237 DEL-anther were found to be associated with 110 meiosis-related genes (DEL-PMC) (Additional file 3: Table S17). Of these targets, six rice meiosis genes, including LOC_Os01g39630 [36] (RAD51C, annotated as DNA repair protein Rad51) predicted by TCONS 00049558, LOC_Os03g58600 [37] (MEL1, encoded PAZ domain containing protein) predicted by TCONS 00068868, and LOC_Os01g68870 [38] (OsMSP1, annotated as leucine-rich repeat receptor protein kinase EXS precursor), LOC_Os02g57270 [39] (OsTBP1, annotated as MYB family transcription factor), LOC_Os08g16610 [40] (OsRad21-3, annotated as $\operatorname{Rad} 21 / \operatorname{Rec} 8$ like protein), and LOC_Os12g31370 [41] (RAD51A2, annotated as DNA repair protein Rad51) predicted by TCONS 00131142, related to the male meiocytes were identified and showed down-regulation in the present study. Thirteen putative meiosis-related genes displayed downregulation in autotetraploid rice anther, such as $L O C_{-}$ Os03g12730 [42] (the homologous Arabidopsis gene is BAM1, annotated as receptor protein kinase CLAVATA1 precursor) predicted by TCONS_00068868, LOC_Os04g30790 [43] (the homologous Arabidopsis gene is XRI1, annotated as expressed protein) and $L O C_{-}$ Os11g12620 [42] (the homologous Arabidopsis gene is BAM1, annotated as receptor protein kinase CLAVATA1 precursor) predicted by TCONS_00055980, LOC_Os12g34510 [44] (the homologous Arabidopsis gene is $\mathrm{H} 2 \mathrm{AX}$, encoded Core histone $\mathrm{H} 2 \mathrm{~A} / \mathrm{H} 2 \mathrm{~B} / \mathrm{H} 3 / \mathrm{H} 4$ domain containing protein) predicted by TCONS 00068868 and TCONS_00121884, and LOC_Os12g41350 [44] (the homologous Arabidopsis gene is ASY1, annotated as meiotic asynaptic mutant 1) predicted by TCONS_00057811. In addition, 13 targets showed meiosis stage-specific gene expressions [32, 33], and 81 targets exhibited differential expression patterns in autotetraploid compared to the diploid rice during meiosis [11]. Of these 81 targets, 28 targets exhibited regulation patterns similar to $\mathrm{Wu}$ et al. [11], such as $L O C_{-}$ Os03g11540 (RPA1B - Putative single-stranded DNA binding complex subunit 1) and LOC_Os05g14590 (MCM6 - Putative minichromosome maintenance MCM complex subunit 6) regulated by TCONS_00055980 and TCONS_00130461, respectively.
Of the targets of DEL-ovary, 20 DEL showed relationship to the meiosis stage (DEL-EMC) (Additional file 3: Table S18), and 39 targets showed EMC specific expressions [34, 35]. Six genes, such as LOC_OsO6g12740 (expressed protein) predicted by TCONS_00121908 and LOC_ Os10g32740 (zinc finger family protein) predicted by TCONS_00114760, were enriched in zygotene and pachytene of EMC [34]. 28 genes showed the highest expressions in late meiosis stage of megasporocyte [34], such as $L O C_{-}$ Os12g39420 (nucleobase-ascorbate transporter), $L O C_{-}$ Os06g44300 (WAX2), LOC_Os08g45170 (carboxyl-terminal peptidase) and LOC_Os05g06460 (dihydrolipoyl dehydrogenase) predicted by TCONS_00144592, TCONS 00037710, TCONS_00121908 and TCONS_00019924, respectively. Interestingly, we found that PMC and EMC meiosis-related DEG were absolutely different, and most of them displayed down-regulation in autotetraploid rice PMC (106/110) and EMC (30/39).

Additionally, 14 meiosis-related DEG displayed protein-protein interactions (PPI) (with 8 and 6 DEG belong to two sub-networks) in EMC, including $L O C_{-}$ Os05g06460 (targeted by TCONS_00019924) interacted with LOC_Os03g18740 (oxidoreductase, short chain dehydrogenase/reductase family, targeted by TCONS 00114760), and LOC_OsO3g15960 (connectivity = 3) annotated as hsp20/alpha crystallin family protein and targeted by TCONS_00144592 (Additional file 1: Fig. S11). A huge PPI network of 47 meiosis-related DEG, predicted by DEL-PMC, was found in PMC. Two subnetworks were established, including one contained two DEG, and the remaining DEG belonged to second subnetwork, which was the main network. Two meiosis DEG, LOC_Os11g12620 (receptor protein kinase CLAVATA1 precursor, regulated by TCONS_00055980) and LOC_Os12g41350 (meiotic asynaptic mutant 1, predicted by TCONS_00057811), as well as LOC_Os01g39630 (RAD51C), were found in this huge sub-network (Additional file 1: Fig. S12).

We categorized the important DELs associated with meiosis-related DEG as shown in Fig. 4, Table 3 and Table 4. The regulatory networks between DELs and DEG may important during anther and ovary development. To confirm the differential expression levels of lncRNAs and target genes, 23 DEL, including 21 DEL-Type 1 and 26 meiosis-related genes were selected to validate the expression patterns using qRT-PCR. The qRT-PCR generally confirmed the high-throughput sequencing results, proving the reliability of RNA-sequencing data used in the present study (Additional file 1: Fig. S13 and S14).

\section{Overexpression of IncRNA57811 reduced rice seed set}

To test the potential functions of the DELs, TCONS $00057811 \quad$ (lncRNA57811), TCONS_00130461 (lncRNA130461) and TCONS_00055980 (lncRNA55980) 


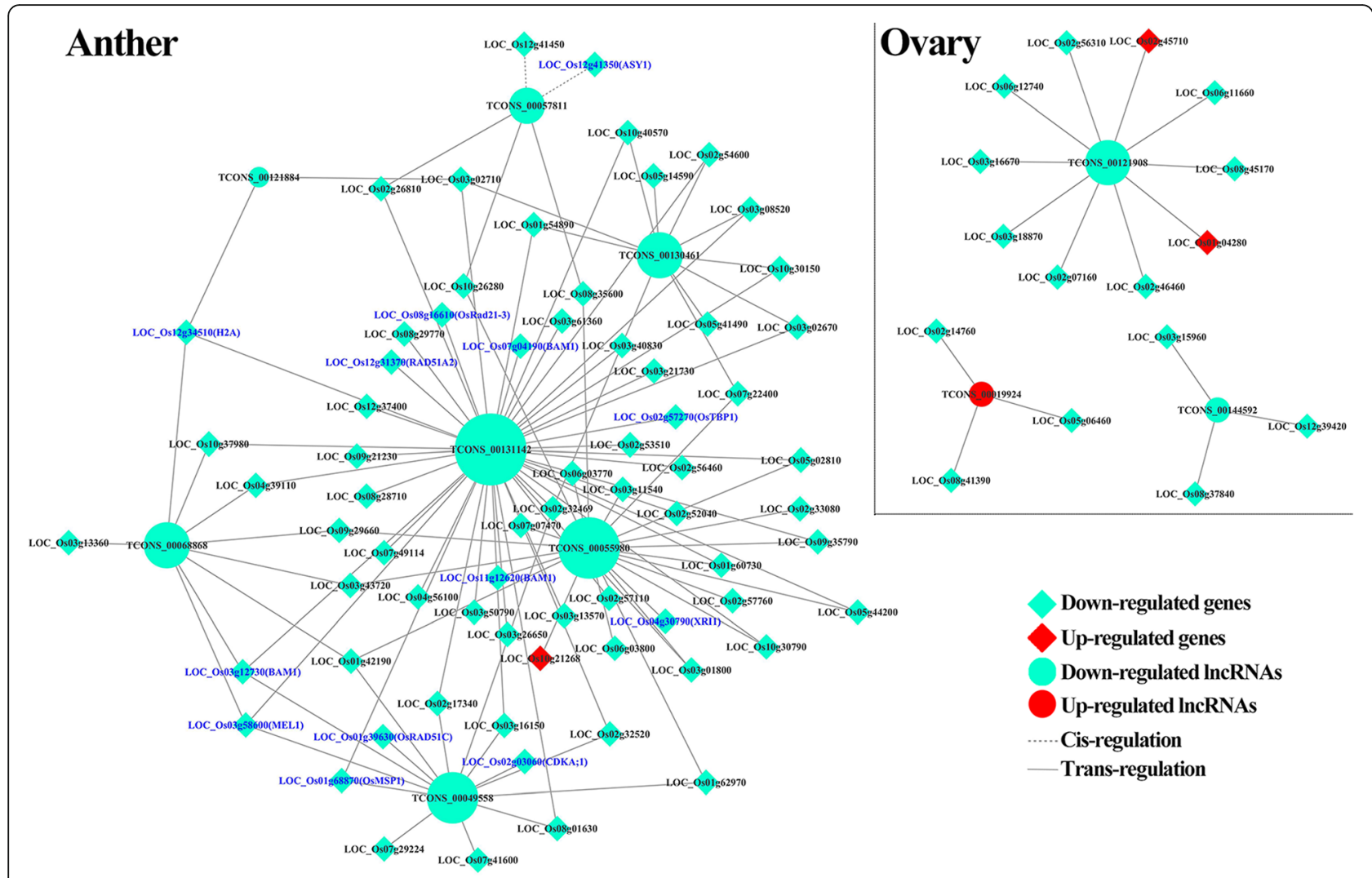

Fig. 4 Prediction of some meiosis-related IncRNA-mRNA association network. The IncRNAs and the target genes showed differential expression patterns and were related to the meiosis. Blue front represents the meiosis genes

were selected for further analysis, which showed antherspecific expression patterns. Of these, lncRNA57811 and lncRNA130461 were highly expressed from pre-meiotic interphase to prophase I during pollen development, whereas lncRNA55980 was highly expressed during late meiosis stage (Fig. 5). Additionally, lncRNA57811 and lncRNA130461 exhibited down-regulation at early meiosis stage, while significantly up-regulated at later meiosis stage in Taichung 65-4x compared to diploid counterpart. Then, the expression patterns of lncRNA57811 were confirmed by GUS stained assays (Fig. 6), and GUS activity was visualized only in anther at early pollen development stage i.e. from pre-meiotic stage to prophase I. The staining intensity decreased dramatically after single microspore stage.

lncRNA57811, lncRNA130461 and lncRNA55980 mutants with the background of Taichung 65 were generated by using CRISPR/Cas9 technology; however, CRISPR/Cas9 editing did not show obvious seed phenotypes in T0 generation. We further focused on the lncRNA57811 by generating its overexpressed mutants, and then planted T1 generation. The seed set of the independent CRISPR lines of lncRNA57811 in T1 generation was similar to the wild type, even though 42 bases deletion was detected on its gene body (Fig. 6,
Additional file 1: Fig. S15). Interestingly, overexpression of lncRNA57811 (57811OE) showed distinctly low seed set compared to wild type in T1 generation (Fig. 7). The seed set of 57811OE-11 and 57811OE-25 lines were 38.61 and $27.55 \%$, respectively. The pollen fertility of 57811 OE was $29.70 \%$, which was significantly lower than the wild type (95.75\%). Furthermore, overexpression and CRISPR mutants of LOC_Os12g41350 (12g) were obtained. $12 \mathrm{~g}$ was preferentially expressed in reproductive tissues, while poorly expressed in vegetative tissues. Overexpression of $12 \mathrm{~g}$ showed similar morphology to wild type (Additional file 1: Fig. S16). One homozygous mutant with an 8 bp deletion, which resulted in premature termination of the protein sequence, was identified in T0 generation. This line displayed semi-sterility with a seed set of $41.13 \%$ in T1 generation. Moreover, $L O C_{-}$ Os12g41350 showed down-regulation in $57811 \mathrm{OE}$ mutants.

\section{Discussion}

LncRNAs associated with rice reproductive development shared common characteristics with other species More than $50 \%$ of lncRNAs showed tissue specific patterns in rice anthers and strawberry pollens, which revealed that the expression patterns of lncRNAs play 
Table 3 List of PMC meiosis-related differentially expressed IncRNAs in the autotetraploid rice

\begin{tabular}{|c|c|c|c|c|c|c|c|}
\hline DEL-PMC & Regulation & Targets & Annotation & Regulation & $\begin{array}{l}\text { small RNAs } \\
\text { precursors }\end{array}$ & $\begin{array}{l}\text { Transposable } \\
\text { elements }\end{array}$ & Reference \\
\hline $\begin{array}{l}\text { TCONS } \\
00026633\end{array}$ & down & $\begin{array}{l}\text { LOC_ } \\
\text { Os08g01630 }\end{array}$ & $\begin{array}{l}\text { DNA repair metallo-beta-lactamase, } \\
\text { putative, expressed }\end{array}$ & down & & $\begin{array}{l}\text { Class I and } \\
\text { Class II }\end{array}$ & Wu et al. [11] \\
\hline $\begin{array}{l}\text { TCONS_ } \\
00049558\end{array}$ & down & $\begin{array}{l}\text { LOC_ } \\
\text { Os01939630 }\end{array}$ & $\begin{array}{l}\text { DNA repair protein Rad51, putative, } \\
\text { expressed }\end{array}$ & down & $\begin{array}{l}\text { TCONS } \\
00049558\left(^{*}\right)\end{array}$ & & $\begin{array}{l}\text { Kou et al. [36] } \\
\text { (RAD51C) }\end{array}$ \\
\hline \multirow[t]{3}{*}{$\begin{array}{l}\text { TCONS } \\
00055980\end{array}$} & down & $\begin{array}{l}\text { LOC- } \\
\text { Os04g30790 }\end{array}$ & expressed protein & down & & & $\begin{array}{l}\text { Dean et al. [43] } \\
\text { (XRI1) }\end{array}$ \\
\hline & down & $\begin{array}{l}\text { LOC- } \\
\text { Os11g12620 }\end{array}$ & $\begin{array}{l}\text { receptor protein kinase CLAVATA1 } \\
\text { precursor, putative, expressed }\end{array}$ & down & & & $\begin{array}{l}\text { Hord et al. [42] } \\
\text { (BAM1) }\end{array}$ \\
\hline & down & $\begin{array}{l}\text { LOC } \\
\text { Os03g11540 }\end{array}$ & $\begin{array}{l}\text { RPA1B - Putative single-stranded DNA } \\
\text { binding complex subunit } 1 \text {, expressed }\end{array}$ & down & & & Wu et al. [11] \\
\hline \multirow[t]{2}{*}{$\begin{array}{l}\text { TCONS_ } \\
00057811\end{array}$} & down & $\begin{array}{l}\text { LOC } \\
\text { Os } 12 g 41350\end{array}$ & $\begin{array}{l}\text { meiotic asynaptic mutant 1, putative, } \\
\text { expressed }\end{array}$ & down & & & $\begin{array}{l}\text { Sanchez-Moran } \\
\text { et al. [44] (ASY1) }\end{array}$ \\
\hline & down & $\begin{array}{l}\text { LOC } \\
\text { Os12g41450 }\end{array}$ & $\begin{array}{l}\text { F-box domain containing protein, } \\
\text { expressed }\end{array}$ & down & & & $\begin{array}{l}\text { Deveshwar et al. } \\
\text { [33] }\end{array}$ \\
\hline \multirow[t]{3}{*}{$\begin{array}{l}\text { TCONS } \\
00068868\end{array}$} & down & $\begin{array}{l}\mathrm{LOC}_{-} \\
\text {Os03g58600 }\end{array}$ & $\begin{array}{l}\text { PAZ domain containing protein, } \\
\text { putative, expressed }\end{array}$ & down & $\begin{array}{l}\text { TCONS } \\
00068868\left(^{*}\right)\end{array}$ & Class II & $\begin{array}{l}\text { Nonomura et al. } \\
\text { [37] (MEL1) }\end{array}$ \\
\hline & down & $\begin{array}{l}\text { LOC } \\
\text { Os03912730 }\end{array}$ & $\begin{array}{l}\text { receptor protein kinase CLAVATA1 } \\
\text { precursor, putative, expressed }\end{array}$ & down & & Class II & $\begin{array}{l}\text { Hord et al. [42] } \\
\text { (BAM1) }\end{array}$ \\
\hline & down & $\begin{array}{l}\text { LOC } \\
\text { Os } 12 g 34510\end{array}$ & $\begin{array}{l}\text { Core histone } \mathrm{H} 2 \mathrm{~A} / \mathrm{H} 2 \mathrm{~B} / \mathrm{H} 3 / \mathrm{H} 4 \text { domain } \\
\text { containing protein, putative, expressed }\end{array}$ & down & & Class ॥ & $\begin{array}{l}\text { Sanchez-Moran } \\
\text { et al. [44] (H2AX) }\end{array}$ \\
\hline $\begin{array}{l}\text { TCONS } \\
00091337\end{array}$ & down & $\begin{array}{l}\text { LOC- } \\
\text { Os01960730 }\end{array}$ & $\begin{array}{l}\text { RING-H2 finger protein, putative, } \\
\text { expressed }\end{array}$ & down & & $\begin{array}{l}\text { Class I and } \\
\text { Class II }\end{array}$ & Wu et al. [11] \\
\hline $\begin{array}{l}\text { TCONS } \\
00121645\end{array}$ & down & $\begin{array}{l}\mathrm{LOC} \\
\text { Os02g57760 }\end{array}$ & O-methyltransferase, putative, expressed & down & $\begin{array}{l}\text { TCONS } \\
00121645(*)\end{array}$ & $\begin{array}{l}\text { Class I and } \\
\text { Class II }\end{array}$ & Fujita et al. [32] \\
\hline $\begin{array}{l}\text { TCONS } \\
00121884\end{array}$ & down & $\begin{array}{l}\text { LOC } \\
\text { Os12g34510 }\end{array}$ & $\begin{array}{l}\text { Core histone } \mathrm{H} 2 \mathrm{~A} / \mathrm{H} 2 \mathrm{~B} / \mathrm{H} 3 / \mathrm{H} 4 \text { domain } \\
\text { containing protein, putative, expressed }\end{array}$ & down & $\begin{array}{l}\text { TCONS } \\
00121884(*)\end{array}$ & $\begin{array}{l}\text { Class I and } \\
\text { Class II }\end{array}$ & $\begin{array}{l}\text { Sanchez-Moran } \\
\text { et al. [44] (H2AX) }\end{array}$ \\
\hline $\begin{array}{l}\text { TCONS } \\
00130461\end{array}$ & down & $\begin{array}{l}\text { LOC- } \\
\text { Os05g14590 }\end{array}$ & $\begin{array}{l}\text { MCM6 - Putative minichromosome } \\
\text { maintenance MCM complex subunit } 6 \text {, } \\
\text { expressed }\end{array}$ & down & $\begin{array}{l}\text { TCONS_ } \\
00130461\left(^{*}\right)\end{array}$ & $\begin{array}{l}\text { Class I and } \\
\text { Class II }\end{array}$ & Wu et al. [11] \\
\hline \multirow[t]{4}{*}{$\begin{array}{l}\text { TCONS } \\
00131142\end{array}$} & down & $\begin{array}{l}\text { LOC- } \\
\text { Os01968870 }\end{array}$ & $\begin{array}{l}\text { leucine-rich repeat receptor protein } \\
\text { kinase EXS precursor, putative, expressed }\end{array}$ & down & $\begin{array}{l}\text { TCONS } \\
00131142\end{array}$ & Class II & $\begin{array}{l}\text { Nonomura et al. } \\
\text { [38] (OsMSP1) }\end{array}$ \\
\hline & down & $\begin{array}{l}\text { LOC_ } \\
\text { Os02957270 }\end{array}$ & $\begin{array}{l}\text { MYB family transcription factor, putative, } \\
\text { expressed }\end{array}$ & down & & Class II & $\begin{array}{l}\text { Hong et al. [39] } \\
\text { (OsTBP1) }\end{array}$ \\
\hline & down & $\begin{array}{l}\text { LOC } \\
\text { Os08g16610 }\end{array}$ & $\begin{array}{l}\text { Rad21/Rec8 like protein, putative, } \\
\text { expressed }\end{array}$ & down & & Class II & $\begin{array}{l}\text { Tao et al. [40] } \\
\text { (OsRad21-3) }\end{array}$ \\
\hline & down & $\begin{array}{l}\text { LOC } \\
\text { Os12g31370 }\end{array}$ & $\begin{array}{l}\text { DNA repair protein Rad51, putative, } \\
\text { expressed }\end{array}$ & down & & Class II & $\begin{array}{l}\text { Morozumi et al. } \\
\text { [41] (RAD51A2) }\end{array}$ \\
\hline $\begin{array}{l}\text { TCONS_- } \\
00136741\end{array}$ & down & $\begin{array}{l}\text { LOC } \\
\text { Os04g43300 }\end{array}$ & $\begin{array}{l}\text { BRCA1 C Terminus domain containing } \\
\text { protein, expressed }\end{array}$ & down & & Class II & Wu et al. [11] \\
\hline
\end{tabular}

Down: down-regulated in autotetraploid rice

Small RNAs precursors: DEL serves as miRNAs/phasiRNAs precursors

Class I: Retrotransposons; Class II: DNA Transposons

$(*)$ : the small RNAs showed differential expression in autotetraploid rice

important role in reproductive tissues [24, 27]. In the present study, we characterized 4859 reliable lncRNAs during meiotic stages of anther and ovary in autotetraploid and diploid rice. These lncRNAs shared similar features with the other mammals and plant species, such as shorter transcript length and lower expression levels than protein-coding genes [45-48]. On the other hand, only a few rice reproductive lncRNAs with conserved sequences among the other plant species were detected, which indicated that rice reproductive IncRNAs may undergo a rapid evolvement [47, 49]. However, 11 lncRNAs were found to be conserved in Arabidopsis, Brachypodium, Zea mays and Sorghum bicolor, which might be the housekeeping lncRNAs and carry out important functions in angiosperms. Moreover, full-length of 10 lncRNAs were obtained by RACE, and six of them were found to be conserved among the neo-tetraploid, autotetraploid, diploid and wild rice, especially IncRNA57811, which indicated that these reproductiverelated lncRNAs may play important functions. 
Table 4 List of EMC meiosis-related differentially expressed IncRNAs in the autotetraploid rice

\begin{tabular}{|c|c|c|c|c|c|c|c|}
\hline DEL-EMC & Regulation & Targets & Annotation & Regulation & $\begin{array}{l}\text { small RNAs } \\
\text { precursors }\end{array}$ & $\begin{array}{l}\text { Transposable } \\
\text { elements }\end{array}$ & Reference \\
\hline $\begin{array}{l}\text { TCONS } \\
00019924\end{array}$ & up & $\begin{array}{l}\text { LOC } \\
\text { Os05g06460 }\end{array}$ & $\begin{array}{l}\text { dihydrolipoyl dehydrogenase, } \\
\text { putative, expressed }\end{array}$ & down & & $\begin{array}{l}\text { Class I and Class } \\
\|\end{array}$ & $\begin{array}{l}\text { Kubo et al. } \\
\text { [34] }\end{array}$ \\
\hline $\begin{array}{l}\text { TCONS_ } \\
00023646\end{array}$ & down & $\begin{array}{l}\text { LOC_ } \\
\text { Os01967850 }\end{array}$ & $\begin{array}{l}\text { zinc finger, RING-type, putative, } \\
\text { expressed }\end{array}$ & down & & $\begin{array}{l}\text { Class I and Class } \\
\|\end{array}$ & $\begin{array}{l}\text { Wu et al. } \\
\text { [35] }\end{array}$ \\
\hline $\begin{array}{l}\text { TCONS_ } \\
00037710\end{array}$ & down & $\begin{array}{l}\text { LOC } \\
\text { Os06 } 944300\end{array}$ & WAX2, putative, expressed & down & & Class II & $\begin{array}{l}\text { Kubo et al. } \\
{[34]}\end{array}$ \\
\hline $\begin{array}{l}\text { TCONS } \\
00115107\end{array}$ & down & $\begin{array}{l}\text { LOC_ } \\
\text { Os01908560 }\end{array}$ & $\begin{array}{l}\text { DnaK family protein, putative, } \\
\text { expressed }\end{array}$ & down & & Class II & $\begin{array}{l}\text { Kubo et al. } \\
{[34]}\end{array}$ \\
\hline \multirow[t]{3}{*}{$\begin{array}{l}\text { TCONS__ } \\
00121908\end{array}$} & down & $\begin{array}{l}\mathrm{LOC}_{-} \\
\mathrm{Os02g} 46460\end{array}$ & $\begin{array}{l}\text { peptide transporter PTR2, } \\
\text { putative, expressed }\end{array}$ & down & & Class II & $\begin{array}{l}\text { Wu et al. } \\
\text { [35] }\end{array}$ \\
\hline & down & $\begin{array}{l}\text { LOC_ } \\
\text { Os06g12740 }\end{array}$ & expressed protein & down & & Class II & $\begin{array}{l}\text { Kubo et al. } \\
\text { [34] }\end{array}$ \\
\hline & down & $\begin{array}{l}\text { LOC_ } \\
\text { Os08g } 45170\end{array}$ & $\begin{array}{l}\text { carboxyl-terminal peptidase, } \\
\text { putative, expressed }\end{array}$ & down & & Class II & $\begin{array}{l}\text { Kubo et al. } \\
{[34]}\end{array}$ \\
\hline $\begin{array}{l}\text { TCONS_ } \\
00134306\end{array}$ & down & 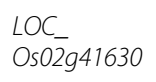 & $\begin{array}{l}\text { phenylalanine ammonia-lyase, } \\
\text { putative, expressed }\end{array}$ & down & & $\begin{array}{l}\text { Class I and Class } \\
\|\end{array}$ & $\begin{array}{l}\text { Kubo et al. } \\
\text { [34] }\end{array}$ \\
\hline \multirow[t]{2}{*}{$\begin{array}{l}\text { TCONS_ } \\
00144592\end{array}$} & down & $\begin{array}{l}\text { LOC_ } \\
\text { Os03g15960 }\end{array}$ & $\begin{array}{l}\text { hsp20/alpha crystallin family } \\
\text { protein, putative, expressed }\end{array}$ & down & & Class II & $\begin{array}{l}\text { Kubo et al. } \\
{[34]}\end{array}$ \\
\hline & down & $\begin{array}{l}\text { LOC_ } \\
\text { Os12g39420 }\end{array}$ & $\begin{array}{l}\text { nucleobase-ascorbate transporter, } \\
\text { putative, expressed }\end{array}$ & down & & Class II & $\begin{array}{l}\text { Kubo et al. } \\
{[34]}\end{array}$ \\
\hline
\end{tabular}

Up: up-regulated in autotetraploid rice

Down: down-regulated in autotetraploid rice

Small RNAs precursors: DEL serves as miRNAs/phasiRNAs precursors

Class I: Retrotransposons; Class II: DNA Transposons

\section{LncRNAs act as small RNAs precursors in autotetraploid rice that might play potential role in PMC and EMC meiosis}

The majority of lncRNAs act as precursors for small RNA, and siRNAs seem to be the major small RNA population and many lncRNAs serve as precursors for siRNAs $[23,25,29]$. According to a previous study about Arabidopsis, the siRNAs are generated by Pol IV, and their precursors are 30-40 nt [50], which is in contrast to the model that IncRNAs could be defined as the transcripts longer than $200 \mathrm{bp}$ [22]. So, we focused on the miRNAs and phasiRNAs, and 37 DEL served as precursors for small RNA and all of them displayed downregulation in autotetraploid rice, which suggested that the down-regulated DEL were associated with small RNAs generation in autotetraploid rice, particularly with anther. PhasiRNAs were found to be associated with male meiocytes in rice and maize [51, 52]. Another study revealed that a SNP in PMS1T (lncRNA), nearby miR2118 recognition site, lead to differential accumulation of the $21 \mathrm{nt}$-phasiRNAs and resulted in male sterility under long-day conditions [53]. Recently, downregulation of 24 nt-phasiRNAs was consistent with osamiR2275d during pollen development in autotetraploid rice [20]. Our results demonstrated that down-regulated DEL, especially DEL-PMC (Type 1), may cause low expression of phasiRNAs, which could harm meiocytes of autotetraploid rice. LncRNAs were predicted to be
miRNAs targets or target mimics in rice and maize [54], however, these results are hard to detect in autotetraploid rice. We speculated that lncRNAs prefer to serve as the small RNA precursors rather than the miRNAs targets or decoys in rice, even in the autotetraploid rice. Moreover, different kinds of predicted targets between DEL and DEM were detected and only few targets (23) were co-regulated by DEL and DEM in our study. These specific targets showed different categories of GO functions in autotetraploid rice anther and ovary, which suggested that lncRNAs and miRNAs take part in various functions during meiosis in autotetraploid rice.

\section{Low expression levels of transposable elements, associated with IncRNAs, may cause great harm to male and female meiocytes in autotetraploid rice}

WGD events are an obvious route to genome expansion, and the increase genome size owing to the rapid proliferation of transposable elements [55]. Over $70 \%$ rice reproductive IncRNAs were associated with TEs in the present study, and these results were consistent with other plant species [25, 56]. Zhang et al. [57] indicated that hypermethylation of class II DNA transposons may suppress the expression of neighboring genes, which become a "genome shock" to adapt the genome-dosage effects in autotetraploid rice. In our previous studies, the differentially expressed siRNAs were found to be associated with TEs during male meiosis, which implied the 


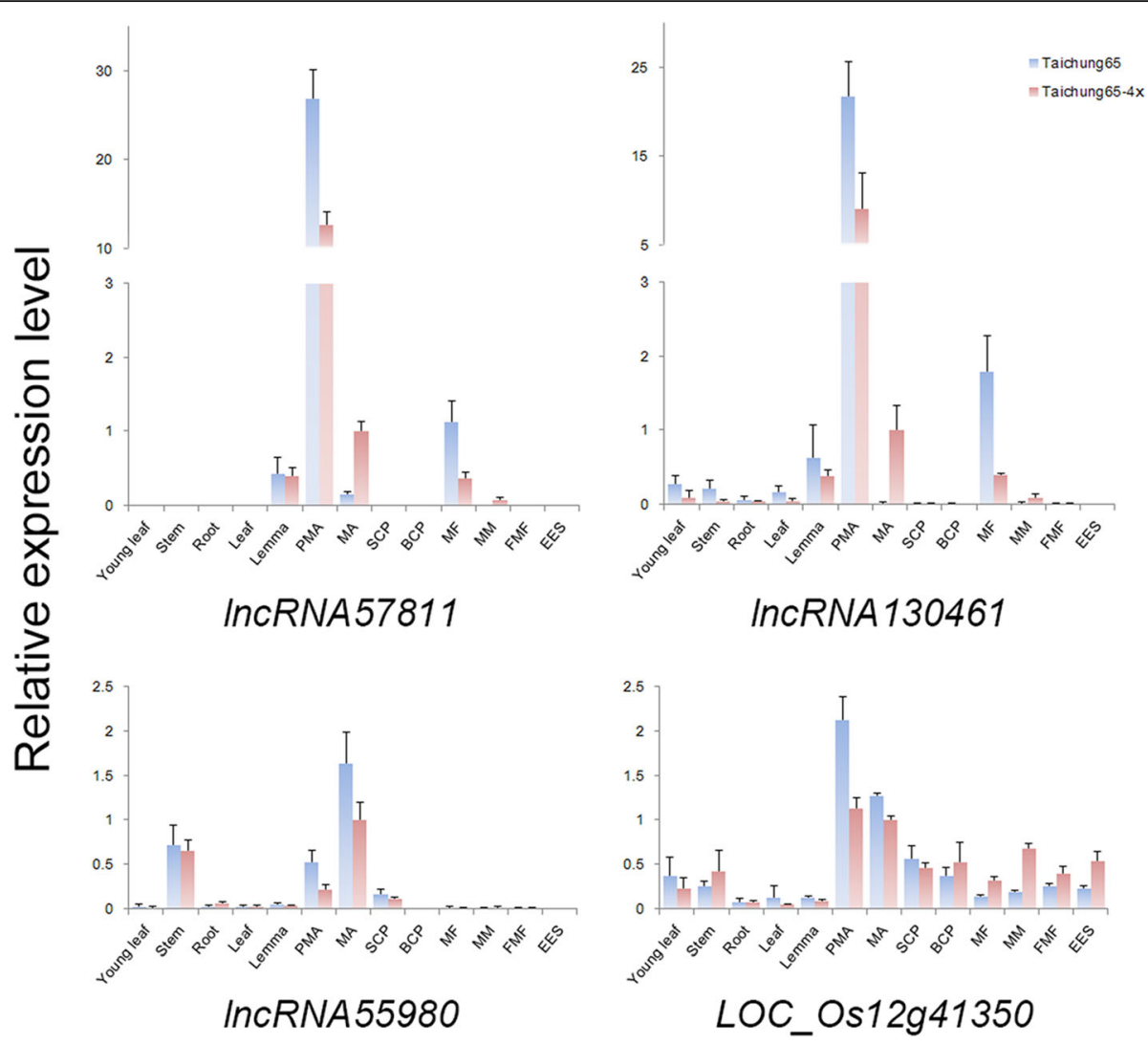

Fig. 5 The expression patterns of IncRNAs in Taichung 65-4x and Taichung 65. PMA: Premeiotic interphase to meiosis prophase I, MA: Metaphase I to meiosis II, SCP: Single microspore developing-stage, BCP: Bi-cellular pollen stage to mature pollen, MF: Megasporocyte formation stage to meiosis prophase I, MM: Megasporocyte metaphase I to meiosis II, FMF: Functional megaspore formation to embryo sac mitotic stage, EES: Eightnucleate embryo sac developing-stage to mature embryo sac. The stage of ovary was corresponding to the stage of anther. Error bars represent the standard deviation (SD) of three biological replicates

relationship between TEs and sterility in autotetraploid rice $[20,21]$. One interesting finding about Arabidopsis male meiocytes illustrated that TEs were abundant and specifically expressed in meiocytes $[58,59]$. The activated TEs only detected in vegetative cells but not in sperm cells of the haploid pollen [60]. Male meiocytes represent the final stage of the diploid phase with reactivated TEs, which may involve in chromatin structures and facilitated the precession of meiosis $[58,59]$. TEslncRNAs detected in male sunflower meiocytes were found to be associated with the different recombination rates between domesticated and wild sunflower [25]. Another study reported that the expression levels of TElncRNAs were the highest in testis [61], and important in the biology of normal testis [62]. We observed low expression levels of TEs and TEs-lncRNAs, and downregulation of TEs-DEL (Helitron and Stowaway families of Class II) in autotetraploid rice may disturb the chromatin structures or have harmful effects on meiocytes. The TEs and TEs-lncRNAs associated with meiocytes required further studies.
Meiosis-related IncRNAs may play key roles during PMC and EMC meiosis in autotetraploid rice

LncRNAs are revealed to execute direct meiotic roles during meiosis $[63,64]$, such as UPGRADE2, which was highly up-regulated and attained neofunctionalization in the context of apomeiosis for pollen development in Boechera species [65], and LDMAR, a SNP could repress the expression level of LDMAR and cause male sterility in rice [26]. Here, 237 DEL-PMC and 20 DEL-EMC were found to be associated with 110 and 39 meiosisrelated genes. Most of these meiosis-related genes showed down-regulation and have protein-protein interactions in autotetraploid rice that related to the abnormal meiosis and sterility in our previous study $[8,11]$, such as LOC_Os01g39630 (RAD51C) and LOC_ Os02g57270 (OsTBP1), which is required for the meiosis of male gametocytes [36, 39]. We detected TCONS 00068868, the DEL-PMC (Type 1), which showed downregulation during meiosis of autotetraploid rice anther, and its target LOC_Os03g58600 (MEL1) showed the same differential expression pattern and validated by 

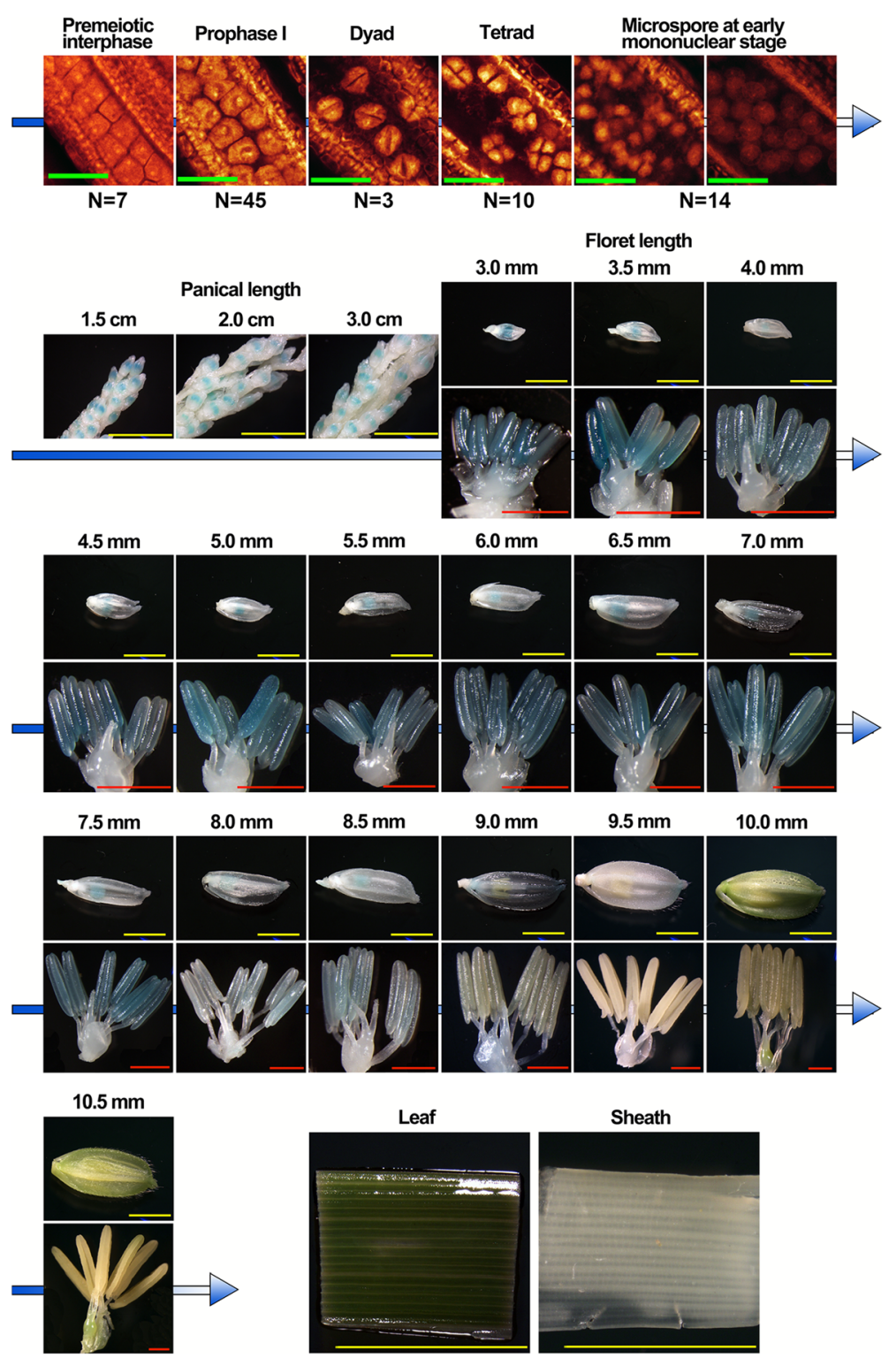

Fig. 6 GUS staining assay of IncRNA57811-Pro::GUS. ' $N$ ' indicates the number of the GUS-stained anthers observed at particular development stage by WE-CLSM. Green Bars $=40 \mu \mathrm{m}$. The stained tissues were photographed using LEICA MZ16. Yellow Bars $=4 \mathrm{~mm}$ and Red Bars $=1 \mathrm{~mm}$

qRT-PCR. Rice MEL1 is a key gene involved in meiosis that regulates the cell division of pre-meiotic germ cells, and the proper modification of meiotic chromosomes $[37,66]$. Moreover, MEL1 was preferentially associated with 21 nt-phasiRNAs, which play important role during meiosis [51]. We speculated that the abnormal expression of MEL1 might cause abnormal meiosis behavior in autotetraploid rice, and the down-regulation of its lncRNA regulators may triggered the abnormal expressions.

In addition, we detected ten DEL-EMC (Type 1) that showed great relationships with the 27 embryo sac meiosisrelated genes [34, 35]. Though the functions of these targets remain largely unknown, they highly expressed and showed meiosis specific expressions during megasporocytes, which suggested their key roles during the meiosis procession of megasporocytes. The regulation of EMC meiosis-related targets in autotetraploid rice was confirmed by the qRT-PCR, such as LOC_Os12g39420, LOC_OsO2g46460 and LOC_ Os05g06460 regulated by TCONS_00144592, TCONS 00121908 and TCONS_00019924, respectively. These lncRNAs/target pairs probably played essential roles and involved in female meiocytes development of autotetraploid rice, and their abnormal expression patterns might have a strong effect on the embryo sac fertility of autotetraploid rice. Overall, the list of meiosis-DELs in rice anther/ovary will be beneficial for future studies in plant reproduction. 

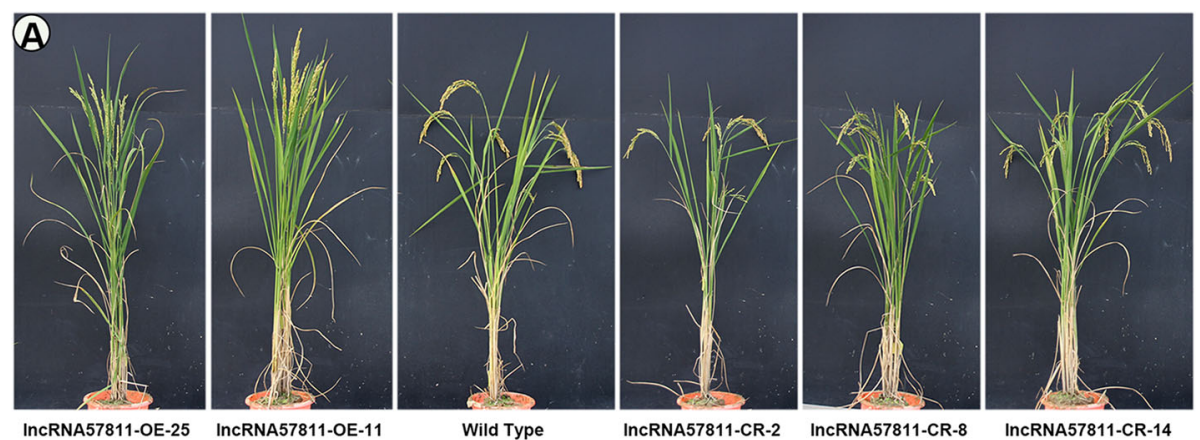

(B)

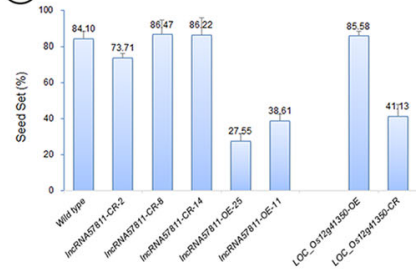

(C)

InCRNA57811-CR-2 InCRNA57811-CR-8

IncRNA57811-CR-14

(E)

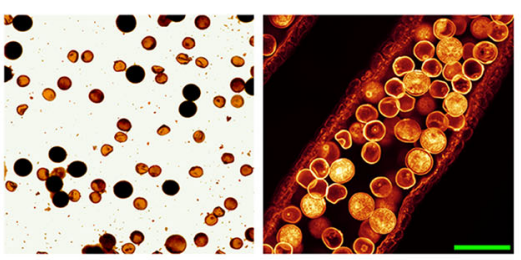

InCRNA57811-OE
(D) $\bar{\Phi}$

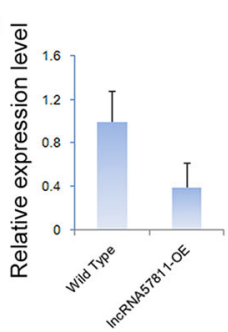

(F)

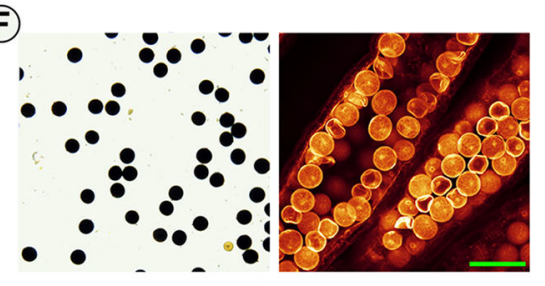

Wild Type

(G) IncRNA57811-CR-2 (homozygote)

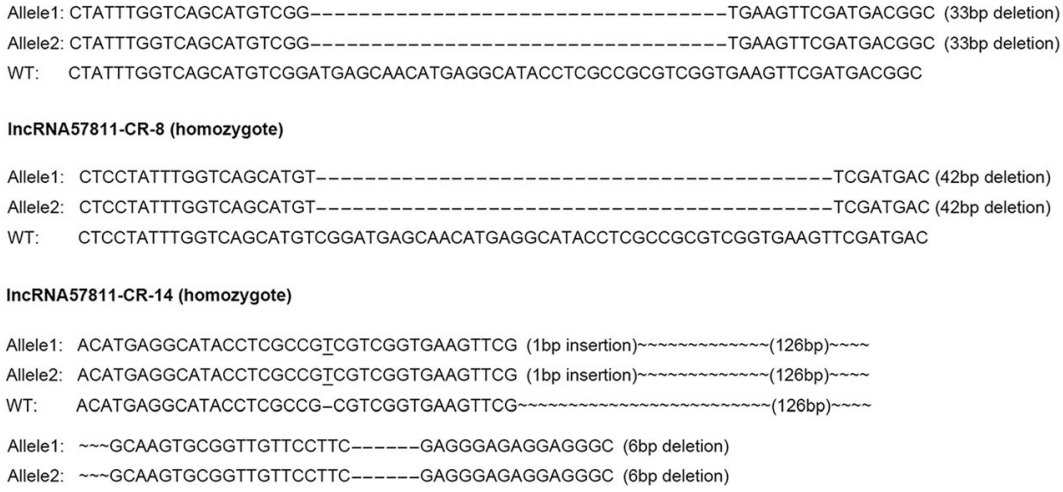

Fig. 7 Phenotype of IncRNA57811-CR and IncRNA57811-OE in T1 generation. a Comparison between the wild-type plant and IncRNA57811 mutant plant after heading. b The seed set of Taichung 65, IncRNA57811-CR and IncRNA57811-OE lines. c IncRNA57811-OE mutants have high expression levels of IncRNA57811 compared to wild type. d LOC_Os12g41350 showed down-regulation in IncRNA57811-OE mutants. e, f IncRNA57811-OE mutants displayed lower pollen fertility than the wild type. g Genotype of IncRNA57811-CR lines

Overexpression of lncRNA57811 showed low seed set and pollen sterility in T1 generation, while CRISPR/Cas9 editing of lncRNA57811 displayed similar morphology when compared to Taichung 65. lncRNA57811 showed anther specific pattern and highly expressed from pre-meiotic interphase to prophase I during pollen development, which demonstrated that IncRNA57811 play key role at early meiosis stage. The higher expression levels of lncRNA57811 were detected in Taichung 65-4x and Taichung 65 at pre meiosis, however, significantly higher expression level of lncRNA57811 was detected in Taichung 65-4x than Taichung 65 during late meiosis stage. These results indicated that the irregular expression pattern of lncRNA57811 might be the main reason for low fertility in Taichung 65-4x. 
For knock-down analysis of lncRNAs, CRISPR/Cas9 editing system should not be a first choice tool. In this study, three lncRNAs were selected for generating the editing-mutant by CRISPR/Cas9; however, no obvious change was observed in morphology. This might be happened because 1) CRISPR/Cas9 usually causes frame shift and base replacement in protein sequences, but lncRNAs are the noncoding RNA and no protein. 2) IncRNAs are full of repetitive sequences, deletions/insertions mutation in one repetitive region, and their functions might be replaced by other repetitive regions. 3) the key regions of lncRNAs have not been be edited successfully so far. 4) the functions of these three lncRNAs could be replaced by other lncRNAs/genes. Recently, Wang et al. [28] used RNAi method to generate the knock-down mutants of lncRNA and acquired desired results. Therefore, there is a need to develop more methods to generate knock-down of lncRNAs in future. Otherwise, more specific-sgRNA targets of CRISPR/Cas9 editing system should be utilized to make sure about the whole/most length of lncRNA to be knocked-out.

LOC_Os12g41350 (meiotic asynaptic mutant 1) was the predicted cis-target of lncRNA57811, and downregulation of LOC_Os12g41350 in Taichung 65-4x was confirmed by qRT-PCR. CRISPR/Cas9 editing of $L O C_{-}$ Os12g41350 showed semi-sterility in T1 generation. Additionally, LOC_Os12g41350 showed down-regulation in lncRNA57811-OE. The homologous gene of $L O C_{-}$ Os12g41350, namely $A S Y 1$, is an important protein required for synapsis and crossover formation during early meiosis in Arabidopsis [44]. Cytological studies have revealed that $A S Y 1$ is localized to the regions of chromatin, associated with the axial/lateral elements of meiotic chromosomes, and required for morphogenesis of the synaptonemal complex [67]. Mutant lines asy1 showed identical asynaptic phenotypes during male meiosis [68]. In addition, homologous asynapsis in meiotic prophase I could induce aneuploidy in autopolyploid Arabidopsis asy1 [69]. Moreover, a single crossover per chromosome (reduce crossover rates) could prevent multivalent formation in autotetraploid plants [18]. We hypothesized that lncRNA57811 might be served as cis-regulatory element of the LOC_Os12g41350 in rice, which resulted in pollen sterility. However, it required further experiments to confirm the relationship between IncRNA57811 and $L O C_{-}$ Os12g41350, and to know whether LOC_Os12g41350 is a cis-target of lncRNA57811. The function and the regulation network of lncRNA57811 and LOC_Os12g41350 during pollen development should be further analyzed.

\section{Conclusion}

In this study, we utilized high-throughput sequencing to identify the long noncoding RNAs associated with meiosis in autotetraploid rice anther and ovary compared to diploid rice. A total of 4859 confident lncRNAs were identified, which shared common features with other species. Ten lncRNAs were validated by RACE assay, and six were found to be conversed in tetraploid rice. Of the DEL, 237 and 20 DEL were identified as PMC meiosis-related DEL and EMC meiosis-related DEL, respectively. Target prediction showed that these meiosis-related DEL were associated with some important meiosis genes. Interestingly, most of them were associated with the transposable elements and could act as small RNAs precursors, especially the anther/ovary-preferred lncRNAs in autotetraploid rice. Overexpression of lncRNA57811 showed low seed set and pollen sterility indicated that lncRNA played important function during pollen development in polyploid rice. Consequently, the significant differential expression profiles of long noncoding RNAs in the autotetraploid rice may play key roles in regulating the reproductive tissues, thus resulting in low fertility and poor seed set. Our findings provide a new insight on long noncoding RNA in autotetraploid rice reproduction.

\section{Methods \\ Plant material}

Autotetraploid rice, Taichung 65-4x, and its diploid rice, Taichung 65, were used in this study. Taichung 65 is a famous japonica cultivar from Taiwan and bred by Taichung agricultural improvement farm in 1929 [70]. Taichung 65 was kindly characterized and provided by Prof. Guiquan Zhang (College of Agriculture, South China Agricultural University), and is being used by our research group since 1989 [11, 71, 72]. Taichung 65 has been deposited in the International Rice Genebank Collection Information System (IRGCIS, http://www.irgcis. irri.org:81/grc/irgcishome.html) with the accession number of 9434 since 1962. Taichung 65-4x was developed from the chromosome doubling of Taichung 65 by colchicine and was self-crossed for more than 30 generations by our research group (Prof. Xiangdong Liu) at South China Agricultural University (Guangzhou, Guangdong, China). The voucher specimen of Taichung $65-4 \mathrm{x}$ has been deposited to our lab but not in any publicly available herbarium. These lines were planted at the experimental farm of South China Agricultural University under field conditions. Anthers at pollen development stages were collected from Taichung $65-4 \mathrm{x}$ and Taichung 65 according to $\mathrm{Wu}$ et al. [11]. The ovary tissues were collected from the same spikelet (corresponding anther). All the samples were stored at $-80^{\circ} \mathrm{C}$ for RNA isolation. Three biological replications were used for each tissue for high-throughput RNA-sequencing.

\section{Transcriptome library construction and sequencing}

Total RNA was extracted from the anthers and ovaries by using Trizol reagent (Invitrogen, CA, USA) following 
the manufacturer's procedure. The quantity and purity of total RNA were analyzed by Bioanalyzer 2100 and RNA 6000 Nano LabChip Kit (Agilent, CA, USA) with RIN number $>7.0$. Approximately $10 \mu \mathrm{g}$ of total RNA was used to deplete ribosomal RNA by using Epicentre Ribo-Zero Gold Kit (Illumina, San Diego, USA). Divalent cations under high temperature were used to break poly(A) - or poly(A) + RNA fractions is into small pieces. The final cDNA library was constructed according to the methodology of mRNA-Seq sample preparation kit (Illumina, San Diego, USA). Finally, the paired-end sequencing was performed by Illumina Hiseq2500 (LC Sciences, Hangzhou, China) with an average insert size of 300 bp ( \pm 50 bp).

\section{Prediction and identification of IncRNAs}

Prior to assembly, the low quality reads including reads containing sequencing adaptors, reads containing sequencing primer, nucleotide with quality score lower than $20(\mathrm{Q}<20)$, were removed. After that, the clean reads were aligned to the Oryza sativa genome (ftp://ftp. jgi-psf.org/pub/compgen/phytozome/.v10.0/Osativa 204 v7.0/assembly/) using TopHat2 package [73]. The aligned reads were then used to assemble transcripts of each sample independently, using Cufflinks program [74]. The expression levels of the assembled transcripts were further calculated and normalized by Cufflinks using the measurement unit of fragments per kilobase of transcript per million fragments (FPKM). The prediction of IncRNAs from RNA-seq data was performed according to Sun et al. [75]. We discarded transcripts shorter than $200 \mathrm{bp}$, exons number less than one and transcripts with FPKM $<0.5$. The transcripts with five class codes information (i.e. 'i', 'j', ' $u$ ', 'o', and ' $x$ ') were extracted. Class codes of ' $\mathrm{u}$ ', ' $\mathrm{i}$ ', and ' $\mathrm{x}$ ' mean that the transcripts are in the intergenic, intronic, and antisense sequence, respectively, of a known gene. Class codes of 'o' and ' $j$ ' mean that the transcripts overlapped with known exons [74]. Then the coding potential of the remaining transcripts was evaluated using coding potential calculator (CPC) software [30] and Coding Noncoding Index (CNCI) software [75]. The transcripts with CPC score < $=-1$ and $\mathrm{CNCI}$ score $<=0$ were identified as the IncRNA candidates. LncRNAs with $P$-value $<0.05$ and $\mid \log 2$ (fold change ratio) $\mid>1$ were considered as differentially expressed lncRNAs.

\section{Small RNA library construction and sequencing}

We further used about $1 \mu \mathrm{g}$ of total RNA for the small RNA sequencing, and then prepare small RNA libraries according to protocol of TruSeq Small RNA Sample Prep Kits (Illumina, San Diego, USA). After that, we executed the single-end sequencing ( $36 \mathrm{bp}$ ) on an Illumina Hiseq2500 at the LC-BIO (Hangzhou, China) according to the manufacturer's protocol. For the miRNAs analysis, the raw data was further processed with an in-house program, ACGT101-miR (LC Sciences, Houston, Texas, USA) [21]. First, the reads with common RNA families (snRNA, tRNA, snoRNA, rRNA), low complexity, repeats, junk and adapter dimers were removed. Then, the unique sequences (18-25 nt in length) were BLASTed to miRBase 20.0 (ftp://mirbase.org/pub/mirbase/) to identify known miRNAs. The novel miRNAs were predicted by using RNAfold software (http://rna.tbi.univie.ac.at/ cgi-bin/RNAWebSuite/RNAfold.cgi). miRNAs with $P$ value $<0.05$ and $\mid \log 2$ (fold change ratio) $\mid>1$ were considered as differentially expressed miRNAs. Targeted genes of differentially expressed miRNAs were predicted by using TargetFinder [76]. For the phasiRNAs analysis, 21 nt- and 24 nt-phasiRNAs were systemically characterized using PhaseTank packet [77]. PhasiRNAs with Pvalue $<0.05$ and $\mid \log 2$ (fold change ratio) $\mid>1$ were considered as differentially expressed phasiRNAs.

\section{Characterization of IncRNAs}

To investigate the conservation of lncRNAs, all the lncRNAs sequences were blasted against the genome sequences of Arabidopsis thaliana (assembly TAIR10), Zea mays (assembly B73 RefGen_v3), Brachypodium distachyon (assembly Brachypodium_distachyon_v2.0) and Sorghum bicolor (assembly Sorbi1) that download from NCBI with a cut-off E-value $<1 \mathrm{e}-10$ by using BLASTN. The lncRNAs with more than $20 \%$ sequence matched to other genomes were defined as conversed lncRNAs. Additionally, we also conducted the IncRNAs associated with repetitive element by Repeat Masker (http://www. repeatmasker.org/; based on the Repeat Database namely repeatmaskerlibraries-20,160,829 from http://www.girinst.org/) with the 'slow' option. To identify the lncRNAs that may act as precursors of miRNAs or phasiRNAs, the small RNAs were aligned to the identified lncRNAs by following the model of Boerner and McGinnis [29]. LncRNAs as targets of miRNAs were predicted by psRNATarget [31], with expectation $\leq 3$ [47]. The target mimics were predicted according to the method of Meng et al. [78].

\section{Target gene prediction and functional analysis of IncRNAs} LncRNAs may play cis- and trans-acting regulation on the genes [47]. Two algorithms were used for cis- and transtarget prediction. The first algorithm was used by python script to detect potential cis target genes (differentially expressed genes) that are physically close to lncRNAs (differentially expressed lncRNAs). The genes transcribed within a $100 \mathrm{~kb}$ window upstream or downstream of lncRNAs were considered as potential cis target genes [79]. The second algorithm was used to identify potential trans targets based on RNA sequence complementarity 
(mRNA-lncRNA) and RNA duplex energy prediction [80, 81]. Based on the RNA duplex energy (Free energy $<-50$ ) assessed by RIsearch algorithms [82], the differentially expressed genes and lncRNAs were considered as potentially involved in trans-interaction. Then, functional analysis of the lncRNAs cis/trans targets were done by using the AgriGO [83]. Significance was expressed as a $P$-value $<0.05$. Protein-protein interaction networks were performed using STRING [84].

\section{Quantitative real-time PCR (qRT-PCR) analysis}

Reverse-transcribed of total RNAs isolated from ovaries and anthers, and qRT-PCR assay were performed according to Li et al. [85]. The qRT-PCR products of each candidate IncRNAs were Sanger sequenced by BGI Genomics, and the amplified fragments were matched to the IncRNAs. The specificity of the amplified fragments was checked using the generated melting curve. GAPDH was used as an internal control gene. All qRT-PCR amplifications were carried out in three replications, and the results are presented as the mean \pm standard deviations. The $2^{-\triangle \Delta C T}$ method was employed to calculate the relative expression level [86]. The primers were designed by Primer 5.0 software, and are listed in Additional file 3: Table S19.

\section{5'- and 3'-rapid amplification of cDNA ends (RACE) assay}

Full-length amplification of lncRNA was performed with SMARTer RACE 5'/3' Kit (Clontech, USA) according to the manufacturer's instructions. PCR was performed with Universal Primer A Mix and gene-specific primers using $5^{\prime} / 3^{\prime}$-cDNA as the template (Additional file 3: Table S19). The 5' - and 3'-RACE products were gelpurified and cloned. At least 12 clones were selected for Sanger sequencing to obtain the longest fragment. Finally, long distance PCR using primers designed from the extreme $5^{\prime}$ and $3^{\prime}$ ends of the candidate lncRNA and the $5^{\prime}-\mathrm{cDNA}$ as a template to generating full-length lncRNA.

\section{Selection of the target site and plasmid construction}

Specific gRNA targeting lncRNA57811, IncRNA55980, and lncRNA130461 were selected using the online tool (http://skl.scau.edu.cn/targetdesign/). The gRNA expression cassettes were generated by overlapping PCR. The target sequences were ligated between the corresponding promoter and sgRNA by the first PCR. The second PCR was used to induce a Bsa restriction site. The amplified fragments were then assembled on the pYLCRISPR/ Cas9Ubi-H binary plasmid. To construct the overexpressed IncRNA57811 vector, the cDNA of lncRNA57811 were obtained and fused into the POX vector (digestion by HindIII and BamHI) using Hieff Clone ${ }^{\bullet}$ Plus One Step Cloning Kit (Hieff, Shanghai,
China). To construct lncRNA57811-Pro::GUS vector, $2.0 \mathrm{~kb}$ upstream of ATG sequence was amplified from Taichung 65 genomic DNA and cloned into pCAMBIA1305.1. These constructs were transferred to Agrobacterium EHA105, and then were transformed into rice callus (Taichung 65). The specific primers are listed in Additional file 3: Table S19.

\section{Supplementary information}

Supplementary information accompanies this paper at https://doi.org/10 1186/s12870-020-2290-0.

Additional file $\mathbf{1}$ Fig. $\mathbf{S 1}$ Identification of the IncRNAs in the rice reproductive tissues. Fig. $\mathbf{S 2}$ Characteristics of IncRNAs in rice reproductive tissues. Fig. $\mathbf{S 3}$ Sequence alignment results between IncRNAs obtained by RACE assay and transcripts predicted by transcriptome. Fig. S4 Phylogenic tree analysis of IncRNAs based on the rice dataset. Fig. S5 Anther and ovary-preferred IncRNAs in diploid (A) and autotetraploid rice (B). Fig. S6 Venn analysis of DEL-anther and DELovary in autotetraploid rice. Fig. S7 Classification of differentially expressed IncRNAs in anther (A) and ovary (B) of autotetraploid rice. Fig. S8 Transposable elements (TEs) associated with IncRNAs in autotetraploid rice. Fig. S9 Validation of the transposable elements (TES) associated genes and TEs-IncRNAs in autotetraploid compared to diploid rice. Fig. S10 Venn analysis of the predicted targets of differentially expressed IncRNAs (DEL) and differentially expressed miRNAs (DEM). Fig. S11 Protein-protein interactions between the EMC meiosis-related targets of differentially expressed IncRNAs. Fig. S12 Protein-protein interactions between the PMC meiosis-related targets of differentially expressed IncRNAs. Fig. S13 Validation of the differentially expressed IncRNAs (DEL) in autotetraploid and diploid rice. Fig. S14 Validation of the targets of differentially expressed IncRNAs in autotetraploid and diploid rice. Fig. S15 Agronomic traits of wild type and mutants in T1 generation. Fig. S16 Phenotypes of LOC_Os12g41350-CR and LOC_Os12g41350-OE in T1 generation.

Additional file $\mathbf{2}$ Table S1. Characteristics of all IncRNAs identified in this study. Table S2. Conservation of IncRNAs in other plant species. Table S3. Differentially expressed IncRNAs (DEL) in anther and ovary of Taichung 65-4x compared to Taichung 65. Table S4. The IncRNAs selected by aligment assay compared to a previous study. Table S5. Summary of known and predicted miRNAs detected in this study. Table S6. Overview of 21 nt- and 24 nt-phasiRNAs detected in this study. Table S7. LncRNAs corresponding to miRNA precursors. Table S8. LncRNAs corresponding to phasiRNA precursors. Table S9. A list of IncRNAs predicted to be the targets of miRNAs. Table S10. Transposable elementsassociated with differentially expressed IncRNAs in autotetraploid rice.

Additional file $\mathbf{3}$ Table S11. Classification of differentially expressed IncRNAs related to transposable elements (TEs) in autotetraploid rice. Table S12. The potential target genes of differentially expressed IncRNAs detected by cis-regulation. Table S13. The potential target genes of differentially expressed IncRNAs detected by trans-regulation. Table S14. GO (Gene Ontology) analysis of predicted targets of differentially expressed IncRNAs. Table S15. Overall information about the predicted targets of differentially expressed miRNAs (DEM). Table S16. GO (Gene Ontology) analysis of predicted targets of differentially expressed IncRNAs and differentially expressed miRNAs. Table S17. The most important IncRNA-target pairs related to PMC meiosis in autotetraploid rice. Table S18. The important IncRNA-target pairs related to EMC meiosis in autotetraploid rice. Table S19. A list of primers used in the present study. Table S20. The information about ten IncRNAs detected by RACE in the present study.

\section{Abbreviations}

DEG: differentially expressed genes; DEL: differentially expressed IncRNAs; DEM: differentially expressed miRNAs; EMC: embryo sac mother cell; PMC: pollen mother cell 


\section{Acknowledgements}

The authors thank Dr. Jinwen Wu, Zhixiong Chen, Lan Wang, and Ms. Shuhong Yu and other lab members for assistance. We are very thankful to Acad. Yaoguang Liu for providing the POX vector and the CRISPR/Cas 9 editing system.

\section{Authors' contributions}

$X D L$ conceived and designed the experiments. XL, MQS and XDL wrote the paper. XL, MSW, SLC, HY, YMJ, ZJL, MQS and LYJ performed the experiment and analyzed the data. All authors read and approved the final version of manuscript.

\section{Funding}

This work was supported by the Guangzhou Science and Technology Key Program (201707020015, XD Liu), National Natural Science Foundation of China (31571625, XD Liu), the Key Realm R \& D Program of Guangdong Province (2018B020202012, ZM Zhang), and China Postdoctoral Science Foundation (2018 M643101, X Li). The funders had no role in the design of the study and collection, analysis, and interpretation of data and in writing of the manuscript.

\section{Availability of data and materials}

Transcriptome and small RNA sequencing data are available from the NCBI under the accession numbers PRJNA395615 (https://www.ncbi.nlm.nih.gov/ bioproject/PRJNA395615) and PRJNA396435 (https://www.ncbi.nlm.nih.gov/ bioproject/PRJNA396435). The accession numbers of ten IncRNAs are MN481253 (IncRNA57811), MN481254 (IncRNA130461), MN481255 (IncRNA55980), MN481256 (IncRNA91337), MN481257 (IncRNA68868), MN481258 (IncRNA111916), MN481259 (IncRNA130471), MN481260 (IncRNA45430), MN481261 (IncRNA13598) and MN481262 (IncRNA121908). The information about IncRNAs are also available in Additional file 3: Table S20. All data supporting the conclusions described here are provided in tables, figures and additional files.

\section{Ethics approval and consent to participate}

Plant samples used in the study were not collected from national park or natural reserve. According to national and local legislation, no specific permission was required for collecting these plants. We confirm that this complies with national guidelines and no formal ethics approval was required in this particular case.

\section{Consent for publication}

Not applicable.

\section{Competing interests}

The authors declare that they have no competing interests.

\section{Author details}

${ }^{1}$ State Key Laboratory for Conservation and Utilization of Subtropical Agro-Bioresources, South China Agricultural University, Guangzhou 510642, China. ${ }^{2}$ Guangdong Provincial Key Laboratory of Plant Molecular Breeding, South China Agricultural University, Guangzhou 510642, China. ${ }^{3}$ College of Agriculture, South China Agricultural University, Guangzhou 510642, China. ${ }^{4}$ Guangdong Laboratory for Lingnan Modern Agriculture, South China Agricultural University, Guangzhou 510642, China.

\section{Received: 12 December 2019 Accepted: 13 February 2020} Published online: 19 February 2020

\section{References}

1. Wendel JF, Jackson SA, Meyers BC, Wing RA. Evolution of plant genome architecture. Genome Biol. 2016;17:37

2. Liu S, Adams KL. Dramatic change in function and expression pattern of a gene duplicated by polyploidy created a paternal effect gene in the Brassicaceae. Mol Biol Evol. 2010;27:2817-28.

3. Hughes TE, Langdale JA, Kelly S. The impact of widespread regulatory neofunctionalization on homeolog gene evolution following wholegenome duplication in maize. Genome Res. 2014;24:1348-55.

4. Mason AS, Snowdon RJ. Oilseed rape: learning about ancient and recent polyploid evolution from a recent crop species. Plant Biol. 2016;18:883-92.
5. Shahid MQ, Liu GF, Li JQ, Naeem M, Liu X. Heterosis and gene action study of agronomic traits in diploid and autotetraploid rice. Acta Agric Scand Sect B Soil Plant Sci. 2011;61:23-32.

6. Guo H, Mendrikahy JN, Xie L, Deng J, Lu Z, Wu J, et al. Transcriptome analysis of neo-tetraploid rice reveals specific differential gene expressions associated with fertility and heterosis. Sci Rep. 2017;7:40139.

7. Shahid MQ, Xu HM, Lin SQ, Chen ZX, Naeem M, Li YJ, et al. Genetic analysis and hybrid vigor study of grain yield and other quantitative traits in autotetraploid rice. Pak J Bot. 2012;44:237-46.

8. Guo H, Feng J, Lu Y, Liu X. Abnormal structure of embryo sac in autotetraploid rice. Rice Sci. 2006;13:257-64.

9. Shahid MQ, Li YJ, Saleem MF, Naeem M, Wei CM, Liu XD. Yield and yield components in autotetraploid and diploid rice genotypes (indica and japonica) sown in early and late seasons. Aust J Crop Sci. 2013;7:632-41.

10. Shahid MQ, Sun J, Wei C, Zhang P, Liu X. Studies on the abnormality of embryo sac and pollen fertility in autotetraploid rice during different growing seasons. Pak J Bot. 2010;42:7-19.

11. Wu J, Shahid MQ, Guo H, Yin W, Chen Z, Wang L, et al. Comparative cytological and transcriptomic analysis of pollen development in autotetraploid and diploid rice. Plant Reprod. 2014;27:181-96.

12. Luo $Q$, Li Y, Shen $Y$, Cheng $Z$. Ten years of gene discovery for meiotic event control in rice. J Genet Genomics. 2014;41:125-37.

13. Cifuentes M, Grandont L, Moore G, Chevre AM, Jenczewski E. Genetic regulation of meiosis in polyploid species: new insights into an old question. New Phytol. 2010;186:29-36.

14. Bomblies K, Madlung A. Polyploidy in the Arabidopsis genus. Chromosom Res. 2014:22:117-34.

15. Szadkowski E, Eber F, Huteau V, Lodé M, Huneau C, Belcram H, et al. The first meiosis of resynthesized Brassica napus, a genome blender. New Phytol. 2010;186:102-12.

16. He JH, Shahid MQ, Li YJ, Guo HB, Cheng XA, Liu XD, et al. Allelic interaction of $F_{1}$ pollen sterility loci and abnormal chromosome behaviour caused pollen sterility in intersubspecific autotetraploid rice hybrids. J Exp Bot. 2011;62:4433-45.

17. Yant L, Hollister JD, Wright KM, Arnold BJ, Higgins JD, Franklin FCH, et al. Meiotic adaptation to genome duplication in Arabidopsis arenosa. Curr Biol. 2013;23:2151-6.

18. Lloyd A, Bomblies K. Meiosis in autopolyploid and allopolyploid Arabidopsis. Curr Opin Plant Biol. 2016;30:116-22.

19. Wu J, Shahid MQ, Chen L, Chen Z, Wang L, Liu X, et al. Polyploidy enhances $F_{1}$ pollen sterility loci interactions that increase meiosis abnormalities and pollen sterility in autotetraploid rice. Plant Physiol. 2015;169:2700-17.

20. Li X, Shahid MQ, Xia J, Lu Z, Fang N, Wang L, et al. Analysis of small RNAs revealed differential expressions during pollen and embryo sac development in autotetraploid rice. BMC Genomics. 2017;18:129.

21. Li X, Shahid MQ, Wu J, Wang L, Liu X, Lu Y. Comparative small RNA analysis of pollen development in autotetraploid and diploid rice. Int J Mol Sci. 2016;17:499.

22. Taylor DH, Chu ET, Spektor R, Soloway PD. Long non-coding RNA regulation of reproduction and development. Mol Reprod Dev. 2015;82:932-56.

23. Li L, Eichten SR, Shimizu R, Petsch K, Yeh CT, Wu W, et al. Genome-wide discovery and characterization of maize long non-coding RNAs. Genome Biol. 2014;15:R40.

24. Kang C, Liu Z. Global identification and analysis of long non-coding RNAs in diploid strawberry Fragaria vesca during flower and fruit development. BMC Genomics. 2015;16:815.

25. Flórez-Zapata NM, Reyes-Valdés MH, Martinez O. Long non-coding RNAs are major contributors to transcriptome changes in sunflower meiocytes with different recombination rates. BMC Genomics. 2016;17:490.

26. Ding J, Lu Q, Ouyang Y, Mao H, Zhang P, Yao J, et al. A long noncoding RNA regulates photoperiod-sensitive male sterility, an essential component of hybrid rice. Proc Natl Acad Sci U S A. 2012;109:2654-9.

27. Zhang YC, Liao JY, Li ZY, Yu Y, Zhang JP, Li QF, et al. Genome-wide screening and functional analysis identify a large number of long noncoding RNAs involved in the sexual reproduction of rice. Genome Biol. 2014; 15:512.

28. Wang Y, Luo X, Sun F, Hu J, Zha X, Su W, et al. Overexpressing IncRNA LAIR increases grain yield and regulates neighbouring gene cluster expression in rice. Nat Commun. 2018;9:3516.

29. Boerner S, McGinnis KM. Computational identification and functional predictions of long noncoding RNA in Zea mays. PLoS One. 2012;7:e43047. 
30. Kong L, Zhang Y, Ye ZQ, Liu XQ, Zhao SQ, Wei L, et al. CPC: assess the protein-coding potential of transcripts using sequence features and support vector machine. Nucleic Acids Res. 2007;35:W345-9.

31. Dai $X$, Zhao PX. psRNATarget: a plant small RNA target analysis server. Nucleic Acids Res. 2011;39:W155-9.

32. Fujita M, Horiuchi $Y$, Ueda $Y$, Mizuta $Y$, Kubo $T$, Yano $K$, et al. Rice expression atlas in reproductive development. Plant Cell Physiol. 2010;51:2060-81.

33. Deveshwar P, Bovill WD, Sharma R, Able JA, Kapoor S. Analysis of anther transcriptomes to identify genes contributing to meiosis and male gametophyte development in rice. BMC Plant Biol. 2011;11:78.

34. Kubo T, Fujita M, Takahashi H, Nakazono M, Tsutsumi N, Kurata N. Transcriptome analysis of developing ovules in rice isolated by laser microdissection. Plant Cell Physiol. 2013;54:750-65.

35. Wu Y, Yang L, Cao A, Wang J. Gene expression profiles in rice developing ovules provided evidence for the role of sporophytic tissue in female gametophyte development. PLoS One. 2015;10:e141613.

36. Kou Y, Chang Y, Li X, Xiao J, Wang S. The rice RAD51C gene is required for the meiosis of both female and male gametocytes and the DNA repair of somatic cells. J Exp Bot. 2012;63:5323-35.

37. Nonomura K, Morohoshi A, Nakano M, Eiguchi M, Miyao A, Hirochika H, et al. A germ cell-specific gene of the ARGONAUTE family is essential for the progression of premeiotic mitosis and meiosis during sporogenesis in rice. Plant Cell. 2007;19:2583-94

38. Nonomura K, Miyoshi K, Eiguchi M, Suzuki T, Miyao A, Hirochika H, et al. The MSP1 gene is necessary to restrict the number of cells entering into male and female sporogenesis and to initiate anther wall formation in rice. Plant Cell. 2003;15:1728-39.

39. Hong JP, Byun MY, Koo DH, An K, Bang JW, Chung IK, et al. Suppression of RICE TELOMERE BINDING PROTEIN 1 results in severe and gradual developmental defects accompanied by genome instability in rice. Plant Cell. 2007;19:1770-81.

40. Tao J, Zhang L, Chong K, Wang T. OsRAD21-3, an orthologue of yeast RAD21, is required for pollen development in Oryza sativa. Plant J. 2007;51:919-30.

41. Morozumi Y, Ino R, Ikawa S, Mimida N, Shimizu T, Toki S, et al. Homologous pairing activities of two rice RAD51 proteins, RAD51A1 and RAD51A2. PLOS One. 2013:8:e75451.

42. Hord CL, Chen C, DeYoung BJ, Clark SE, Ma H. The BAM1/BAM2 receptorlike kinases are important regulators of Arabidopsis early anther development. Plant Cell. 2006;18:1667-80.

43. Dean PJ, Siwiec T, Waterworth WM, Schlögelhofer P, Armstrong SJ, West CE. A novel ATM-dependent X-ray-inducible gene is essential for both plant meiosis and gametogenesis. Plant J. 2009;58:791-802.

44. Sanchez-Moran E, Santos JL, Jones GH, Franklin FC. ASY1 mediates AtDMC1dependent interhomolog recombination during meiosis in Arabidopsis. Genes Dev. 2007:21:2220-33.

45. Pauli A, Valen E, Lin MF, Garber M, Vastenhouw NL, Levin JZ, et al. Systematic identification of long noncoding RNAs expressed during zebrafish embryogenesis. Genome Res. 2012;22:577-91.

46. Song $X$, Liu G, Huang Z, Duan W, Tan H, Li Y, et al. Temperature expression patterns of genes and their coexpression with LncRNAs revealed by RNASeq in non-heading Chinese cabbage. BMC Genomics. 2016;17:297.

47. Tian J, Song Y, Du Q, Yang X, Ci D, Chen J, et al. Population genomic analysis of gibberellin-responsive long non-coding RNAs in Populus. J Exp Bot. 2016;67:2467-82.

48. Gao X, Ye J, Yang C, Zhang K, Li X, Luo L, et al. Screening and evaluating of long noncoding RNAs in the puberty of goats. BMC Genomics. 2017;18:164.

49. Zhang G, Duan A, Zhang J, He C. Genome-wide analysis of long noncoding RNAs at the mature stage of sea buckthorn (Hippophae rhamnoides Linn) fruit. Gene. 2017;596:130-6.

50. Zhai J, Bischof S, Wang H, Feng S, Lee TF, Teng C, et al. A one precursor one siRNA model for pol IV-dependent siRNA biogenesis. Cell. 2015;163: 445-55.

51. Komiya R, Ohyanagi H, Niihama M, Watanabe T, Nakano M, Kurata N, et al. Rice germline-specific Argonaute MEL1 protein binds to phasiRNAs generated from more than 700 lincRNAs. Plant J. 2014;78:385-97.

52. Zhai J, Zhang H, Arikit S, Huang K, Nan GL, Walbot V, et al. Spatiotemporally dynamic, cell-type-dependent premeiotic and meiotic phasiRNAs in maize anthers. Proc Natl Acad Sci U S A. 2015:112:3146-51.

53. Fan $Y$, Yang J, Mathioni SM, Yu J, Shen J, Yang X, et al. PMS1T, producing phased small-interfering RNAs, regulates photoperiod-sensitive male sterility in rice. Proc Natl Acad Sci U S A. 2016;113:15144-9.
54. Wu HJ, Wang ZM, Wang M, Wang XJ. Widespread long noncoding RNAs as endogenous target mimics for MicroRNAs in plants. Plant Physiol. 2013;161: 1875-84.

55. Verde I, Abbott AG, Scalabrin S, Jung S, Shu S, Marroni F, et al. The highquality draft genome of peach (Prunus persica) identifies unique patterns of genetic diversity, domestication and genome evolution. Nat Genet. 2013;45: 487-94.

56. Wang X, Ai G, Zhang C, Cui L, Wang J, Li H, et al. Expression and diversification analysis reveals transposable elements play important roles in the origin of Lycopersicon-specific IncRNAs in tomato. New Phytol. 2016; 209:1442-55.

57. Zhang J, Liu Y, Xia EH, Yao QY, Liu XD, Gao LZ. Autotetraploid rice methylome analysis reveals methylation variation of transposable elements and their effects on gene expression. Proc Natl Acad Sci U S A. 2015;112: E7022-9.

58. Chen C, Farmer AD, Langley RJ, Mudge J, Crow JA, May GD, et al. Meiosisspecific gene discovery in plants: RNA-Seq applied to isolated Arabidopsis male meiocytes. BMC Plant Biol. 2010;10:280.

59. Yang $H$, Lu P, Wang $Y$, Ma H. The transcriptome landscape of Arabidopsis male meiocytes from high-throughput sequencing: the complexity and evolution of the meiotic process. Plant J. 2011;65:503-16.

60. Slotkin RK, Vaughn M, Borges F, Tanurdzić M, Becker JD, Feijó JA, et al. Epigenetic reprogramming and small RNA silencing of transposable elements in pollen. Cell. 2009;136:461-72.

61. Kelley D, Rinn J. Transposable elements reveal a stem cell-specific class of long noncoding RNAs. Genome Biol. 2012;13:R107.

62. Young JM, Whiddon JL, Yao Z, Kasinathan B, Snider L, Geng LN, et al. DUX4 binding to retroelements creates promoters that are active in FSHD muscle and testis. PLoS Genet. 2013;9:e1003947.

63. Hongay CF, Grisafi PL, Galitski T, Fink GR. Antisense transcription controls cell fate in Saccharomyces cerevisiae. Cell. 2006;127:735-45.

64. van Werven FJ, Neuert G, Hendrick N, Lardenois A, Buratowski S, van Oudenaarden A, et al. Transcription of two long noncoding RNAs mediates mating-type control of gametogenesis in budding yeast. Cell. 2012;150: 1170-81.

65. Mau M, Corral JM, Vogel H, Melzer M, Fuchs J, Kuhlmann M, et al. The conserved chimeric transcript UPGRADE2 is associated with unreduced pollen formation and is exclusively found in apomictic Boechera species. Plant Physiol. 2013;163:1640-59.

66. Liu H, Nonomura K. A wide reprogramming of histone $\mathrm{H} 3$ modifications during male meiosis I in rice is dependent on the Argonaute protein MEL1. J Cell Sci. 2016;129:3553-61.

67. Armstrong SJ, Caryl AP, Jones GH, Franklin FC. Asy1, a protein required for meiotic chromosome synapsis, localizes to axis-associated chromatin in Arabidopsis and Brassica. J Cell Sci. 2002:115:3645-55.

68. Caryl AP, Armstrong SJ, Jones GH, Franklin FC. A homologue of the yeast HOP1 gene is inactivated in the Arabidopsis meiotic mutant asy1. Chromosoma. 2000;109:62-71.

69. Wei F, Zhang GS. Meiotically asynapsis-induced aneuploidy in autopolyploid Arabidopsis thaliana. J Plant Res. 2010;123:87-95.

70. Lin SC, Min SK. Chinese rice varieties and their family tree. Shanghai: Shanghai science and technology press; 1991. (in Chinese).

71. Shahid MQ, Chen FY, Li HY, Wang SZ, Chen FF, et al. Double-neutral genes, $S a-n$ and $S b-n$, for pollen fertility in rice to overcome indicaxjaponica hybrid sterility. Crop Sci. 2013:53:164-76.

72. Zhang GQ, Lu YG. Genetic studies of the hybrid sterility in cultivated rice (Oryza sativa) I. Diallel analysis of the hybrid sterility among isogenic $F_{1}$ sterile lines. Rice Sci. 1989;3:97-101.

73. Kim D, Pertea G, Trapnell C, Pimentel H, Kelley R, Salzberg SL. TopHat2: accurate alignment of transcriptomes in the presence of insertions, deletions and gene fusions. Genome Biol. 2013;14:R36.

74. Trapnell C, Roberts A, Goff L, Pertea G, Kim D, Kelley DR, et al. Differential gene and transcript expression analysis of RNA-seq experiments with TopHat and cufflinks. Nat Protoc. 2012:7:562-78.

75. Sun L, Luo H, Bu D, Zhao G, Yu K, Zhang C, et al. Utilizing sequence intrinsic composition to classify protein-coding and long non-coding transcripts. Nucleic Acids Res. 2013;41:e166.

76. Fahlgren N, Carrington JC. miRNA target prediction in plants. Methods Mol Biol. 2010;592:51-7.

77. Guo Q, Qu X, Jin W. PhaseTank: genome-wide computational identification of phasiRNAs and their regulatory cascades. Bioinformatics. 2015;31:284-6. 
78. Meng $Y$, Shao $C$, Wang $H$, Jin $Y$. Target mimics: an embedded layer of microRNA-involved gene regulatory networks in plants. BMC Genomics. 2012;13:197.

79. Liu Y, Sun Y, Li Y, Bai H, Xue F, Xu S, et al. Analyses of long non-coding RNA and mRNA profiling using RNA sequencing in chicken testis with extreme sperm motility. Sci Rep. 2017;7:9055.

80. Shi Y, Tu H, Chen X, Zhang Y, Chen L, Liu Z, et al. The long non-coding RNA expression profile of Coxsackievirus A16 infected RD cells identified by RNAseq. Virol Sin. 2016:31:131-41.

81. Danis J, Göblös A, Bata-Csörgő Z, Kemény L, Széll M. PRINS non-coding RNA regulates nucleic acid-induced innate immune responses of human keratinocytes. Front Immunol. 2017;8:1053.

82. Wenzel A, Akbasli E, Gorodkin J. Rlsearch: fast RNA-RNA interaction search using a simplified nearest-neighbor energy model. Bioinformatics. 2012;28: 2738-46.

83. Du Z, Zhou X, Ling Y, Zhang Z, Su Z. agriGO: a GO analysis toolkit for the agricultural community. Nucleic Acids Res. 2010;38:W64-70.

84. Szklarczyk D, Franceschini A, Wyder S, Forslund K, Heller D, Huerta-Cepas J, et al. STRING v10: protein-protein interaction networks, integrated over the tree of life. Nucleic Acids Res. 2015;43:D447-52.

85. Li X, Yu H, Jiao Y, Shahid MQ, Wu J, Liu X. Genome-wide analysis of DNA polymorphisms, the methylome and transcriptome revealed that multiple factors are associated with low pollen fertility in autotetraploid rice. PLoS One. 2018;13:e0201854.

86. Livak KJ, Schmittgen TD. Analysis of relative gene expression data using real-time quantitative PCR and the $2^{-\Delta \Delta C T}$ method. Methods. 2001;25:402-8.

\section{Publisher's Note}

Springer Nature remains neutral with regard to jurisdictional claims in published maps and institutional affiliations.

Ready to submit your research? Choose BMC and benefit from:

- fast, convenient online submission

- thorough peer review by experienced researchers in your field

- rapid publication on acceptance

- support for research data, including large and complex data types

- gold Open Access which fosters wider collaboration and increased citations

- maximum visibility for your research: over $100 \mathrm{M}$ website views per year

At BMC, research is always in progress.

Learn more biomedcentral.com/submissions 